\title{
Azo-Containing Polymers with Degradation On-Demand Feature
}

\author{
Mathieu A. Ayer ${ }^{1}$, Yoan C. Simon ${ }^{1,2}$, Christoph Weder ${ }^{1 *}$ \\ ${ }^{\text {I}}$ Adolphe Merkle Institute, University of Fribourg, Chemin des Verdiers 4, 1700 Fribourg, \\ Switzerland \\ ${ }^{2}$ School of Polymers and High Performance Materials, The University of Southern Mississippi, \\ 118 College Dr., Hattiesburg MS 39406, USA
}

ABSTRACT. Molecules comprising aliphatic azo moieties are widely used as radical polymerization initiators, but only few studies have explored their usefulness as stimuliresponsive motifs in macromolecular constructs. The controlled degradation of azo-containing polymers has indeed remained largely unexplored. Here we present the syntheses of linear azocontaining polyamides and polyurethanes and report on their thermally and optically induced responses in solution and the solid state. We show that the stimuli-induced degradation behavior depends strongly on the nature of the polymer backbone, the state of matter, and in solution, on the nature of the solvent. The stimuli-responsive solid-state properties of the azo-containing materials may be particularly useful. In the case of the polyurethanes studied here, temperatureor light-induced cleavage of the azo motifs led to a controllable decrease of the molecular weight, which in turn caused a reduction of the elongation at break, modulus and strength. The controlled degradation of the polymer in well-defined areas can be readily achieved via photopatterning, and this approach was shown to be useful to produce solid structures with graded mechanical properties. 


\section{INTRODUCTION}

Polymers which can be degraded on command, i.e., upon exposure to a pre-defined external stimulus, are of great interest in the context of recycling, ${ }^{1}$ debonding-on-demand adhesives, ${ }^{2}$ small molecules release, ${ }^{3}$ biomedical applications, ${ }^{1}$ sensors, ${ }^{4}$ and many other applications ${ }^{5,6}$ To achieve degradability, a variety of concepts have been investigated, including the introduction of chemically labile groups (such as esters or acetals), ${ }^{7}$ the design of self-immolative polymers (which undergo depolymerization upon cleavage of stimuli-responsive end-groups), ${ }^{8}$ the stimulidriven disassembly of supramolecular polymers, ${ }^{2}$ the (dis)assembly of nanoparticles based on polymers exhibiting a lower critical solution temperature (LCST), ${ }^{9}$ and the introduction of stimuli-responsive moieties that can be preferentially cleaved upon exposure to a specific stimulus or a combination thereof., ${ }^{1,10}$ In addition to hydrolyzable or biodegradable motifs resulting from polycondensation, ${ }^{1,7}$ the introduction of specific light- and heat-sensitive "weak links" has been broadly explored, e.g. spiropyrans, phtalaldehydes, disulfides, Diels-Alder products, and $o$-nitrobenzyl ester or ether motifs. ${ }^{1,8,10,11}$ Remarkably, the degradation characteristics of most of these systems were studied in solution, while examples of controlled light or heat triggered degradation in the solid have been less frequently explored ${ }^{11,12}$ or involved a solid-liquid interface..$^{13}$ In many cases, the degradation process involves a depolymerization reaction. ${ }^{8}$ Interestingly, azo motifs, which are extensively used as radical polymerization initiators, have not been used in the context of controlled polymer degradation. These motifs are however well known to dissociate upon heating, exposure to light, and ultrasonication, and have previously been incorporated into various polymers. The latter were used as radical macroinitiators for the synthesis of well-defined block copolymers, ${ }^{14-21}$ the fabrication of crosslinked PMMA microspheres, ${ }^{22}$ and for the release of molecules grafted onto nanoparticles in 
imaging or delivery applications. ${ }^{23,24}$ It was also shown that the azo-motif can be used to create mechanoresponsive materials that can be degraded upon ultrasonication in solution. ${ }^{25}$ We show here that polyamides and polyurethanes comprising 4,4' -azobis(4-cyanovaleric acid) or 2,2'azobis[2-methyl-N-(2-hydroxyethyl)propionamide] residues in the backbone display mechanical characteristics that are virtually identical to those of the azo-free reference materials. However, these materials can be degraded "on command" upon heating or exposure to (ultraviolet) light. Interestingly, the stimulus-induced degradation behavior of the two azo-motif containing polymers shows significant differences, which highlight the importance of minor design variations.

\section{EXPERIMENTAL SECTION}

Materials. Anhydrous $N$-methyl-2-pyrrolidone (NMP, Sigma-Aldrich) was used as solvent for the synthesis of the polyamides. Fresh inhibitor-free anhydrous tetrahydrofuran (THF) (SigmaAldrich) was utilized as solvent for the synthesis of the polyurethanes and film casting. Stabilized anhydrous THF (Sigma-Aldrich) was employed for controlled degradation experiments taking place in solution. Jeffamine ED-2003 (JA, number-average molecular weight, $M_{\mathrm{n}}=2,000 \mathrm{~g} / \mathrm{mol}$ ), kindly provided by Huntsman Corp., and 1,10-diaminodecane (DAD) were dried in vacuo overnight prior to use. Poly(tetrahydrofuran) (PTHF, $M_{\mathrm{n}}=2,000 \mathrm{~g} / \mathrm{mol}$ ) was dried in vacuo at $100{ }^{\circ} \mathrm{C}$ for $1 \mathrm{~h}$ prior to reaction. 4,4'-Methylenebis(phenyl isocyanate) (MDI) and 1,4-butanediol (BDO) were distilled under vacuum and stored over molecular sieves at $5{ }^{\circ} \mathrm{C}$. 4,4'-Azobis(4-cyanovaleric chloride) (ACVC, 1) was synthesized by adapting procedures

described in the literature. ${ }^{20,21} 2,2^{\prime}$-Azobis[2-methyl-N-(2-hydroxyethyl)propionamide] (2) was generously donated by Wako Pure Chemicals Industries, Ltd. (VA-086). Compound 2 was dried 
in vacuo at rt overnight prior to reaction. All other reagents were purchased from Sigma-Aldrich and used as received.

Instrumentation. ${ }^{1} \mathrm{H}$ NMR and ${ }^{13} \mathrm{C}$ NMR spectra were recorded on Bruker Avance III or Avance III HD spectrometers at 300 or $400 \mathrm{MHz}\left({ }^{1} \mathrm{H}\right)$ and 75 or $100 \mathrm{MHz}\left({ }^{13} \mathrm{C}\right)$, respectively. The chemical shifts $(\delta)$ are reported in parts per million $(\mathrm{ppm}$,$) relative to tetramethylsilane,$ although referencing was based on residual solvent protons. Size exclusion chromatography (SEC) measurements were carried out on an Agilent Technologies 1200 system equipped with a Wyatt Optilab rEX differential refractive index (dRI) detector and a Wyatt miniDAWN TREOS multi-angle laser light scattering (MALLS) detector. The column system was composed of an a Agilent $5 \mu \mathrm{m}$ MIXED-C guard column and either a PLgel $5 \mu \mathrm{m}$ MIXED-C (200-2,000,000 $\mathrm{g} / \mathrm{mol})$ column or a $5 \mu \mathrm{m}$ MIXED-D (200-400,000 g/mol) column from Agilent. THF was employed as solvent/eluent and the measurements were carried out at a flow rate of $1 \mathrm{~mL} / \mathrm{min}$. The mass-average molecular weight $\left(M_{\mathrm{w}}\right)$ and $M_{\mathrm{n}}$ values were determined in comparison with polystyrene standards. Thermogravimetric analysis (TGA) measurements were carried out under $\mathrm{N}_{2}$ with a Mettler-Toledo Star ${ }^{\mathrm{e}}$ system by heating from $25^{\circ} \mathrm{C}$ to $500{ }^{\circ} \mathrm{C}$ at a rate of $10{ }^{\circ} \mathrm{C} / \mathrm{min}$. Differential scanning calorimetry (DSC) measurements were carried out under $\mathrm{N}_{2}$ on MettlerToledo Star ${ }^{\mathrm{e}}$ DSC or DSC 2 systems at heating and cooling rates of $10{ }^{\circ} \mathrm{C} / \mathrm{min}$. Elemental analyses (EA) were performed on a CE Instruments EA 1110 by flash combustion and GC separation. Fourier transform infrared (FT-IR) spectra were recorded on a PerkinElmer Spectrum 65 spectrometer equipped with an attenuated total reflection (ATR) accessory. Ultraviolet-visible (UV-Vis) spectra were measured on a Shimadzu UV-2401PC spectrophotometer. Dynamic mechanical analyses (DMA) were carried out under $\mathrm{N}_{2}$ on a TA Instruments DMA Q800 at a heating rate of $3{ }^{\circ} \mathrm{C} / \mathrm{min}$, a frequency of $1 \mathrm{~Hz}$ and an amplitude of $15 \mu \mathrm{m}$. Stress-strain 
measurements were performed under ambient conditions with a Zwick/Roell Z010 tensile tester mounted with a $200 \mathrm{~N}$ load cell at a strain rate of $150 \mathrm{~mm} / \mathrm{min}$, using dogbone-shaped specimens (total length: $75 \mathrm{~mm}$; cross-section: $4.1 \mathrm{~mm}$; length of measured part: $30 \mathrm{~mm}$ ) that were cut from polymer films with a Zwick/Roell ZCP 020 manual cutting press mounted with the corresponding mold.

Synthesis of 4,4' -azobis(4-cyanovaleric chloride) (ACVC, 1). In a dried two-neck $100 \mathrm{~mL}$ round-bottomed flask connected to a trap containing a concentrated aqueous $\mathrm{NaOH}$ solution and an $\mathrm{N}_{2}$ inlet, 4,4' -azobis(4-cyanovaleric acid) (ACVA, $1.50 \mathrm{~g}, 4.73 \mathrm{mmol}$ ) was dissolved in thionyl chloride $(15 \mathrm{~mL})$ at $0{ }^{\circ} \mathrm{C}$ under magnetic stirring. The reaction mixture was allowed to warm to rt and was stirred under a continuous flow of $\mathrm{N}_{2}$ for $4 \mathrm{~h}$, before an additional portion of thionyl chloride $(5 \mathrm{~mL})$ was added. The reaction mixture was stirred overnight at $\mathrm{rt}$ under $\mathrm{N}_{2}$. At this point, all of the thionyl chloride had evaporated, and the residue was dissolved in chloroform (3 mL) and slowly pipetted into cold pentane $(300 \mathrm{~mL})$. The resulting precipitate was collected by filtration. To remove unreacted $\mathbf{1}$, the residue was dissolved in dichloromethane (DCM, 2 $\mathrm{mL})$, the solution was filtered and the solvent was evaporated. After drying in vacuo, 1 (1.124 $\mathrm{g}$, $75 \%$ yield $)$ was obtained as a pale yellow powder. ${ }^{1} \mathrm{H} \mathrm{NMR}\left(\mathrm{CDCl}_{3}, 300 \mathrm{MHz}\right): \delta=3.24-2.90$ (m, 4H, $\left.\mathrm{CH}_{2}-\mathrm{COCl}\right), 2.66-2.41\left(\mathrm{~m}, 4 \mathrm{H}, \mathrm{CH}_{2}\right), 1.73\left(\mathrm{~d}, 6 \mathrm{H}, \mathrm{CH}_{3}\right)$.

Synthesis of polyamides. Azo-PA was prepared as follows: In a dried two-neck 50 mL roundbottomed flask equipped with septa, JA $\left(M_{\mathrm{n}}=2,000 \mathrm{~g} / \mathrm{mol}, 1.603 \mathrm{~g}, 0.802 \mathrm{mmol}\right)$ and DAD (0.035 g, $0.200 \mathrm{mmol})$ were dissolved in NMP (10 mL) under $\mathrm{N}_{2}$ atmosphere. The clear solution was cooled to $0{ }^{\circ} \mathrm{C}$, propylene oxide (PO, $\mathrm{HCl}$ scavenger, $0.249 \mathrm{~g}, 4.3 \mathrm{mmol}$ ), sebacoyl chloride (SC, $0.191 \mathrm{~g}, 0.797 \mathrm{mmol})$ and $1(0.064 \mathrm{~g}, 0.202 \mathrm{mmol})$ were added. After stirring for $30 \mathrm{~min}$, the cooling bath was removed and the reaction was allowed to proceed at $\mathrm{rt}$ under constant ma- 
gnetic agitation. After 4 days, the clear reaction mixture was slowly precipitated into cold diethyl ether $(400 \mathrm{~mL})$ and the white precipitate that formed was collected by filtration and finally dried in vacuo overnight. Azo-PA was obtained as a pale yellow solid (1.285 g, 68\%). ${ }^{1} \mathrm{H}$ NMR $\left(\mathrm{CDCl}_{3}, 400 \mathrm{MHz}\right): \delta=\mathrm{JA}$ residue: $4.10(\mathrm{~m}, 2 \mathrm{H}, \mathrm{CH}-\mathrm{NH}), 3.81\left(\mathrm{~d}, 4 \mathrm{H}, \mathrm{CH}_{2}\right), 3.80\left(\mathrm{~d}, 4 \mathrm{H}, \mathrm{CH}_{2}\right)$, 3.68-3.35 (m, $\mathrm{CH}_{2} / \mathrm{CH}$, obstructed), $3.63\left(\mathrm{~s}, 4 \mathrm{H}, \mathrm{CH}_{2}\right), 1.29$ (s, $\left.3 \mathrm{H}, \mathrm{CH}_{3}\right)$; DAD residue: 3.22 (q, 4H, $\mathrm{CH}_{2}-\mathrm{CO}$ ), 1.48 (quint, $4 \mathrm{H}, \mathrm{CH}_{2}$ ), 1.17-1.08 (m, $14 \mathrm{H}, \mathrm{CH}_{2}$, obstructed); $\mathrm{SC}$ residue: 2.15 (t, 4H, $\mathrm{CH}_{2}-\mathrm{CO}$ ), 1.60 (quint, $4 \mathrm{H}, \mathrm{CH}_{2}$ ), 1.17-1.08 (m, 8H, $\mathrm{CH}_{2}$, obstructed); 1 residue: $2.46-2.25$ (m, 4H, $\mathrm{CH}_{2}$, obstructed), 2.10-2.00 (m, 4H, $\mathrm{CH}_{2}$, obstructed); 1.70 (d, $6 \mathrm{H}, \mathrm{CH}_{3}$ ). Amides: 6.26 (s, 1H, NH), $5.96(\mathrm{~s}, 1 \mathrm{H}, \mathrm{NH})$. End groups: $5.09\left(\mathrm{~m}, 1 \mathrm{H}, \mathrm{CH}-\mathrm{NH}_{2}\right), 3.35\left(\mathrm{t}, 2 \mathrm{H}, \mathrm{CH}_{2}-\mathrm{CO}\right) .{ }^{13} \mathrm{C}$ $\operatorname{NMR}\left(\mathrm{CDCl}_{3}, 100 \mathrm{MHz}\right): \delta=172.75,75.53,75.33,75.17,73.39,72.40,72.09,70.88,70.70$, $45.42,45.26,36.93,29.37,29.25,25.88,17.97,17.89,17.39,17.30,17.19,17.10)$. Anal. Calcd for $\left(\mathrm{JA}_{0.802} \mathrm{DAD}_{0.200} \mathrm{SC}_{0.797} \mathbf{1}_{0.202}\right)_{\mathrm{n}}: \mathrm{C}, 57.03 ; \mathrm{H}, 9.41 ; \mathrm{N}, 2.04$. Found: C, 56.5; H, 9.8; N, 2.0.

Ref-PA was synthesized using the same procedure, but $\mathbf{1}$ was omitted and the following quantities were used: JA (1.604 g, $0.802 \mathrm{mmol})$, DAD (0.036 g, $0.209 \mathrm{mmol})$, NMP (10 mL), PO (0.249 g, $4.287 \mathrm{mmol})$, SC (0.247 g, $1.031 \mathrm{mmol})$. Ref-PA was obtained as a white solid (1.607 g, 85\%). ${ }^{1} \mathrm{H}$ NMR $\left(\mathrm{CDCl}_{3}, 400 \mathrm{MHz}\right): \delta=\mathrm{JA}$ residue: $4.09(\mathrm{~m}, 2 \mathrm{H}, \mathrm{CH}-\mathrm{NH}), 3.81\left(\mathrm{~d}, 4 \mathrm{H}, \mathrm{CH}_{2}\right)$, 3.79 (d, $\left.4 \mathrm{H}, \mathrm{CH}_{2}\right), 3.68-3.35$ (m, $\mathrm{CH}_{2} / \mathrm{CH}$, obstructed), $3.63\left(\mathrm{~s}, 4 \mathrm{H}, \mathrm{CH}_{2}\right), 1.28$ (s, $\left.3 \mathrm{H}, \mathrm{CH}_{3}\right)$; DAD residue: 3.22 (q, $4 \mathrm{H}, \mathrm{CH}_{2}-\mathrm{CO}$ ), 1.49 (quint, $4 \mathrm{H}, \mathrm{CH}_{2}$ ), 1.17-1.08 (m, $14 \mathrm{H}, \mathrm{CH}_{2}$, obstructed); $\mathrm{SC}$ residue: $2.13\left(\mathrm{t}, 4 \mathrm{H}, \mathrm{CH}_{2}-\mathrm{CO}\right.$ ), 1.60 (quint, $4 \mathrm{H}, \mathrm{CH}_{2}$ ), 1.17-1.08 (m, 8H, $\mathrm{CH}_{2}$, obstructed); Amides: 6.30 (s, 1H, NH), $6.02(\mathrm{~s}, 1 \mathrm{H}, \mathrm{NH})$. End groups: 5.09 (m, 1H, CH-NH${ }_{2}$, 3.35 (t, $2 \mathrm{H}, \mathrm{CH}_{2}-\mathrm{CO}$, obstructed). ${ }^{13} \mathrm{C}$ NMR $\left(\mathrm{CDCl}_{3}, 100 \mathrm{MHz}\right):$ 172.97, 75.51, 75.31, 72.31, $72.04,70.69,45.51,45.34,36.80,29.32,29.09,25.88,17.82,17.27,17.15$. Anal. Calcd for $\left(\mathrm{JA}_{0.802} \mathrm{DAD}_{0.209} \mathrm{SC}_{1.031}\right)_{\mathrm{n}}: \mathrm{C}, 57.30 ; \mathrm{H}, 9.51 ; \mathrm{N}, 1.47$. Found: $\mathrm{C}, 56.2 ; \mathrm{H}, 9.9 ; \mathrm{N}, 1.4$ 
Synthesis of polyurethanes. Azo-PU was prepared as follows: In a dried two-neck $100 \mathrm{~mL}$ round-bottomed flask equipped with septa, PTHF $\left(M_{\mathrm{n}}=2000 \mathrm{~g} / \mathrm{mol}, 4.214 \mathrm{~g}, 2.107 \mathrm{mmol}\right)$ and 2 $(0.346 \mathrm{~g}, 1.200 \mathrm{mmol})$ were stirred in THF $(20 \mathrm{~mL})$ under $\mathrm{N}_{2}$ to afford a white dispersion. BDO $(0.356 \mathrm{~g}, 3.950 \mathrm{mmol})$ was then added dropwise with a syringe. A solution of MDI (1.991 g, $7.957 \mathrm{mmol}, \mathrm{NCO} / \mathrm{OH}$ molar ratio ca. 1.10$)$ in THF $(10 \mathrm{~mL})$ was rapidly added with a syringe. Finally, dibutyltin dilaurate (DBTDL, 3 drops) was added with a syringe and the homogeneous reaction mixture was stirred at $\mathrm{rt}$ for $48 \mathrm{~h}$. At this time, FT-IR analysis revealed the disappearance of the $\mathrm{NCO}$ signals at $2282 \mathrm{~cm}^{-1}$, and the polymer was precipitated into EtOH $(2 \times 800 \mathrm{~mL})$. The resulting precipitate was collected by filtration and dried in vacuo. Azo-PU was obtained as a white fibrous, rubbery solid $(5.823 \mathrm{~g}, 84 \%) .{ }^{1} \mathrm{H}$ NMR $\left(\mathrm{THF}^{\mathrm{d}} \mathrm{d}_{8}, 400 \mathrm{MHz}\right): \delta=$ MDI residue: $9.57(\mathrm{~s}, 2 \mathrm{H}, \mathrm{NH}), 9.55(\mathrm{~s}, 2 \mathrm{H}, \mathrm{NH}), 7.36(\mathrm{~d}, 4 \mathrm{H}, \mathrm{ArH}), 7.04(\mathrm{~d}, 4 \mathrm{H}, \mathrm{ArH}), 3.82(\mathrm{~s}$, 2H, $\mathrm{CH}_{2}$-Ar); PTHF residue: 4.10 (t, 4H, $\left.\mathrm{CH}_{2}-\mathrm{OOC}\right), 3.37$ (s, $\left.108 \mathrm{H}, \mathrm{CH}_{2}-\mathrm{O}\right), 1.69$ (s, 4H, $\mathrm{CH}_{2}$ ), 1.59 (s, $\left.108 \mathrm{H}, \mathrm{CH}_{2}\right)$; BDO residue: 4.13 (d, $\left.4 \mathrm{H}, \mathrm{CH}_{2}-\mathrm{O}\right), 1.73\left(4 \mathrm{H}, \mathrm{CH}_{2}\right.$ obstructed); 2 residue: $8.69(\mathrm{~s}, 2 \mathrm{H}, \mathrm{NH}), 7.30(\mathrm{~s}, 2 \mathrm{H}, \mathrm{NH}), 4.16\left(\mathrm{t}, 4 \mathrm{H}, \mathrm{CH}_{2}-\mathrm{OOC}\right), 3.48\left(\mathrm{q}, 4 \mathrm{H}, \mathrm{CH}_{2}-\mathrm{NH}\right), 1.33(\mathrm{~s}, 12 \mathrm{H}$, $\mathrm{CH}_{3}$ ); end groups: $6.82(\mathrm{~d}, 2 \mathrm{H}, \mathrm{ArH}), 6.47(\mathrm{~d}, 2 \mathrm{H}, \mathrm{ArH}), 4.65\left(\mathrm{~s}, 2 \mathrm{H}, \mathrm{NH}_{2}\right) \cdot{ }^{13} \mathrm{C} \mathrm{NMR}\left(\mathrm{THF}-\mathrm{d}_{8}\right.$, $100 \mathrm{MHz}): \delta=173.94$ (2 residue), 154.37, 138.73, 138.64, 136.43, 136.33, 129.87 (2), 129.83, 119.15, 118.97, 75.72 (2), 71.45, 71.38, 71.01, 65.01, 64.75, 63.66 (2), 41.32, 40.12 (2), 27.70, 27.35, 27.10, 26.80, 23.39 (2). Anal. Calcd for $\left(\mathrm{MDI}_{7.957} \mathrm{BDO}_{3.950} \mathrm{PTHF}_{2.107} \mathbf{2}_{1.200}\right)_{\mathrm{n}}$ : C, 66.29; H, 8.98; N, 4.20. Found: C, 65.62; 9.25; N, 3.88 .

Ref-PU was synthesized using the same procedure, but $\mathbf{2}$ was omitted and the reaction was conducted at a larger scale, using the following quantities: PTHF (9.994 g, $4.997 \mathrm{mmol})$, BDO (0.837 g, $9.284 \mathrm{mmol}$ ), MDI (3.945 g, $15.765 \mathrm{mmol}$ ), DBTDL (4 drops). Ref-PU was obtained as a white fibrous, rubbery solid $(13.298 \mathrm{~g}, 90 \%) .{ }^{1} \mathrm{H}$ NMR $\left(\right.$ THF- $\left.\mathrm{d}_{8}, 400 \mathrm{MHz}\right): \delta=$ MDI 
residue: 9.57 (s, 2H, NH), $9.54(\mathrm{~s}, 2 \mathrm{H}, \mathrm{NH}), 7.36$ (d, 4H, ArH), 7.03 (d, 4H, ArH), 3.82 (s, 2H, $\mathrm{CH}_{2}$-Ar); PTHF residue: 4.09 (t, 4H, $\left.\mathrm{CH}_{2}-\mathrm{OOC}\right), 3.37$ (s, 108H, $\left.\mathrm{CH}_{2}-\mathrm{O}\right), 1.69$ (s, 4H, $\left.\mathrm{CH}_{2}\right), 1.58$ (s, $108 \mathrm{H}, \mathrm{CH}_{2}$ ); $\mathrm{BDO}$ residue: 4.13 (d, $\left.4 \mathrm{H}, \mathrm{CH}_{2}-\mathrm{O}\right), 1.73$ (4H, $\mathrm{CH}_{2}$ obstructed); end groups: 6.82 (d, 2H ArH), 6.47 (d, 2H ArH), $4.65\left(\mathrm{~s}, 2 \mathrm{H}, \mathrm{NH}_{2}\right) .{ }^{13} \mathrm{C} \mathrm{NMR}\left(\mathrm{THF}_{8}, 100 \mathrm{MHz}\right): \delta=154.37$, $138.73,138.64,136.43,136.33,129.83,119.15,118.97,71.45,71.38,71.01,65.00,64.75,41.32$, 27.70, 27.35, 27.10, 26.80. Anal. Calcd for $\left(\mathrm{MDI}_{15.765} \mathrm{BDO}_{9.284} \mathrm{PTHF}_{4.997}\right)_{\mathrm{n}}: \mathrm{C}, 66.90 ; \mathrm{H}, 9.27 ; \mathrm{N}$, 2.99. Found: C, 66.33; 9.53; N, 2.87 .

Polymer film preparation. For films with a diameter of $6.5 \mathrm{~cm}$, solutions of the various polymers (ca. $0.5 \mathrm{~g}$ ) in THF (10 mL) were cast into round $25 \mathrm{~mL}$ poly(tetrafluoroethylene) (PTFE) Petri dishes $(65 \times 12 \mathrm{~mm})$, which were subsequently placed in a well-ventilated hood under an inverted funnel that was used to control the evaporation rate of the solvent so that the films dried overnight under ambient conditions. Drying was completed in vacuo at rt overnight and transparent films with a thickness of ca. 110-120 $\mu \mathrm{m}$ were obtained of all polymers. Films thus prepared were used for the characterization of physical properties (TGA, DSC, EA, UV-Vis, DMA) and for controlled degradation experiments in the solid state. Films with a diameter of 10 $\mathrm{cm}$ were produced by the same process, but using ca. $1.5 \mathrm{~g}$ of the polymer, $30 \mathrm{~mL} \mathrm{THF}$, and a larger Petri dish $(102 \times 20 \mathrm{~mm})$. These samples, which also had a thickness of ca. 110-120 $\mu \mathrm{m}$, were cut into dogbone-shaped specimens (total length: $75 \mathrm{~mm}$; cross-section: $4.1 \mathrm{~mm}$; length of measured part: $30 \mathrm{~mm}$ ) that were used for stress-strain measurements. The sample used in Figure 6 had a thickness of $180 \mu \mathrm{m}$.

Controlled degradation by heat or light treatment. Before any degradation experiments either in solution or solid state, the polymer film samples were dried in vacuo at rt for at least 1 h. For degradation experiments carried out in solution, 2 or $5 \mathrm{~mL}$ pressure-withstanding 
microwave vials were used and a small amount of polymer film (ca. 5-10 mg) was dissolved in the desired solvent at a concentration of $2.5 \mathrm{mg} / \mathrm{mL}$, before the vial was sealed and rapidly heated to the desired temperature $\left(140-160{ }^{\circ} \mathrm{C}\right)$, reached and probed precisely using a Biotage Initiator 2.5 microwave synthesizer. These temperatures were achievable under formation of a light pressure (ca. 3 bar). After maintaining this temperature for $5 \mathrm{~min}$, the solution was cooled to rt, the solvent was removed in vacuo overnight, and the residue was dissolved in THF for SEC analysis. For heat-induced degradation experiments carried out in the solid state, the samples were placed in a Carver CE Press that had been preheated to the desired temperature (140-160 $\left.{ }^{\circ} \mathrm{C}\right)$ under very light pressure between two PTFE sheets and kept in the press for the desired time (5-10 min). Irradiation of the polymer films with UV light was done with a Hönle Bluepoint 4 Ecocure UV lamp equipped with an optical fiber and a 320-390 nm filter; the power density was $600 \mathrm{~mW} / \mathrm{cm}^{2}$ and the distance between the optical fiber and the sample was kept at $15 \mathrm{~mm}$. UV light treatments in solution were applied to polymer solutions $(1 \mathrm{~mL}$ vial, $2.5 \mathrm{mg} / \mathrm{mL})$ under the same conditions. Irradiation of solid-state samples with visible light involved the same setup, but a $390-500 \mathrm{~nm}$ filter was used and the fiber-sample distance was increased to $35 \mathrm{~mm}$. In this particular case, the emission spectrum was measured with an Ocean Optics USB4000 spectrometer and the surface temperature of the films during irradiation experiments was monitored using an Optris PI 160 infrared camera.

The temperature- and light-induced changes to the polymers in the solid state were studied by SEC, ${ }^{1} \mathrm{H}$ NMR spectroscopy, and EA. The SEC measurements were performed after dissolving the samples in THF $(2.5 \mathrm{mg} / \mathrm{mL})$ following the respective treatment. The ${ }^{1} \mathrm{H}$ NMR spectra were recorded after application of a thermal stimulus (exposure to $140{ }^{\circ} \mathrm{C}$ for $5 \mathrm{~min}$ in the case of the PAs and $150{ }^{\circ} \mathrm{C}$ for $5 \mathrm{~min}$ and $30 \mathrm{~min}$ in the case of the PUs) and subsequent dissolution in 
deuterated solvent. The EA measurements were carried out several hours after heating $\left(140{ }^{\circ} \mathrm{C}\right.$ for $5 \mathrm{~min}$ for the PAs and $150{ }^{\circ} \mathrm{C}$ for $5 \mathrm{~min}$ for the PUs).

\section{RESULTS AND DISCUSSION}

\section{Design of materials, synthesis, characterization}

4,4' -Azobis(4-cyanovaleric chloride) (1) and 2,2'-azobis[2-methyl-N-(2-hydroxyethyl)propionamide] (2) were used here as potentially degradable monomers in the syntheses of polyamides (PAs) and polyurethanes (PUs), respectively (Scheme 1). These azo-compounds are widely used as initiators in radical polymerization reactions, which exploit that upon homolytic dissociation of the $\mathrm{C}-\mathrm{N}$ bonds, $\mathrm{N}_{2}$ is released and two carbon-centered radicals are formed, which serve as the chain-initiating species. Azo compounds such as $\mathbf{1}$ and $\mathbf{2}$ display rather low thermal dissociation energies (of the order of $130-150 \mathrm{~kJ} / \mathrm{mol}$ ), which translate into $10 \mathrm{~h}$ half-life temperatures of $69{ }^{\circ} \mathrm{C}$ for the diacid precursor of $\mathbf{1}$ and of $86{ }^{\circ} \mathrm{C}$ for 2 (measured in aqueous solutions). ${ }^{26}$ We speculated that the thermal stability of these motifs might be sufficiently high to allow for the synthesis and processing of the targeted polymers, but low enough to permit controlled degradation by way of selective cleavage of the azo-motifs vs. all other bonds comprised in the polymer backbones. The presence of peripheral functional groups, i.e., carboxylic acid chlorides and alcohols in the case of $\mathbf{1}$ and $\mathbf{2}$, respectively, permits the incorporation of these azo compounds into the backbone of the targeted polymers. We note that the choice of the substituents on the carbon atoms adjacent to the $\mathrm{N}=\mathrm{N}$ bond (i.e. methyl, methylene and nitrile in the case of $\mathbf{1}$ and two methyl and an amide in the case of 2) influences the stability of the resulting radicals; thus the dissociation energy and temperature can readily be tuned within substantial ranges. ${ }^{27,28}$ Moreover, certain azo motifs, including the ones utilized 
here, can also be photolytically cleaved, as they absorb in the near UV range due to the Q $\rightarrow \mathrm{N}$ transition resulting from the approximate $\mathrm{sp}^{3}$ hybridization of the nitrogen lone electron pair orbital. The subsequent homolytic $\mathrm{C}-\mathrm{N}$ bond cleavage occurs either due to a simultaneous dissociation of both bonds of the excited state molecule or through the decomposition of the very unstable $\mathrm{RN}_{2} \cdot$ radical intermediate..$^{27,29,30}$ Thus, $\mathbf{1}$ and $\mathbf{2}$ should be useful for the design of thermally as well as optically degradable polymers.

We elected to synthesize and explore an azo-motif containing polyamide (azo-PA) as well as a corresponding polyurethane (azo-PU), both with a segmented structure composed of hard and soft segments, with the goal of creating materials that exhibit a high toughness, and which would retain some mechanical integrity after dissociation of (some of) the azo motifs comprised in the macromolecules. As this requires a number-average molecular weight $\left(M_{\mathrm{n}}\right)$ of the order of $15,000-20,000 \mathrm{~g} / \mathrm{mol}$, we limited the fraction of azo compounds $\mathbf{1}$ and $\mathbf{2}$ in the feed to $10 \mathrm{~mol} \%$ (corresponding to $3.5 \% \mathrm{w} / \mathrm{w}$ ) in the case of the azo-PA and $8 \mathrm{~mol} \%$ (corresponding to $5 \% \mathrm{w} / \mathrm{w}$ ) in the case of the azo-PU. For reference purposes, the corresponding polymers without azo moieties were also synthesized (ref-PA and ref-PU). Hard blocks, providing physical crosslinks, were composed of $\mathrm{H}$-bonding amides formed by the reaction of 1,10-diaminodecane (DAD) and sebacoyl chloride (SC) in the case of the PAs, and of urethanes resulting from the reaction of butane diol (BDO) and 4,4'-methylenebis(phenyl isocyanate) (MDI) in the case of the PUs, while an amine-terminated poly(propylene glycol-block-ethylene glycol-block-propylene glycol) telechelic (Jeffamine, JA) and telechelic poly(tetrahydrofuran) (PTHF), were used as soft blocks for the PAs and PUs, respectively. Interestingly, as will be discussed later, the two polymer families exhibit different thermal dissociation characteristics depending on the azo motifs they contain. 
Scheme 1. Synthesis of the azo-group containing polyamide azo-PA and polyurethane azoPU and the corresponding azo-free reference polymers ref-PA and ref-PU.
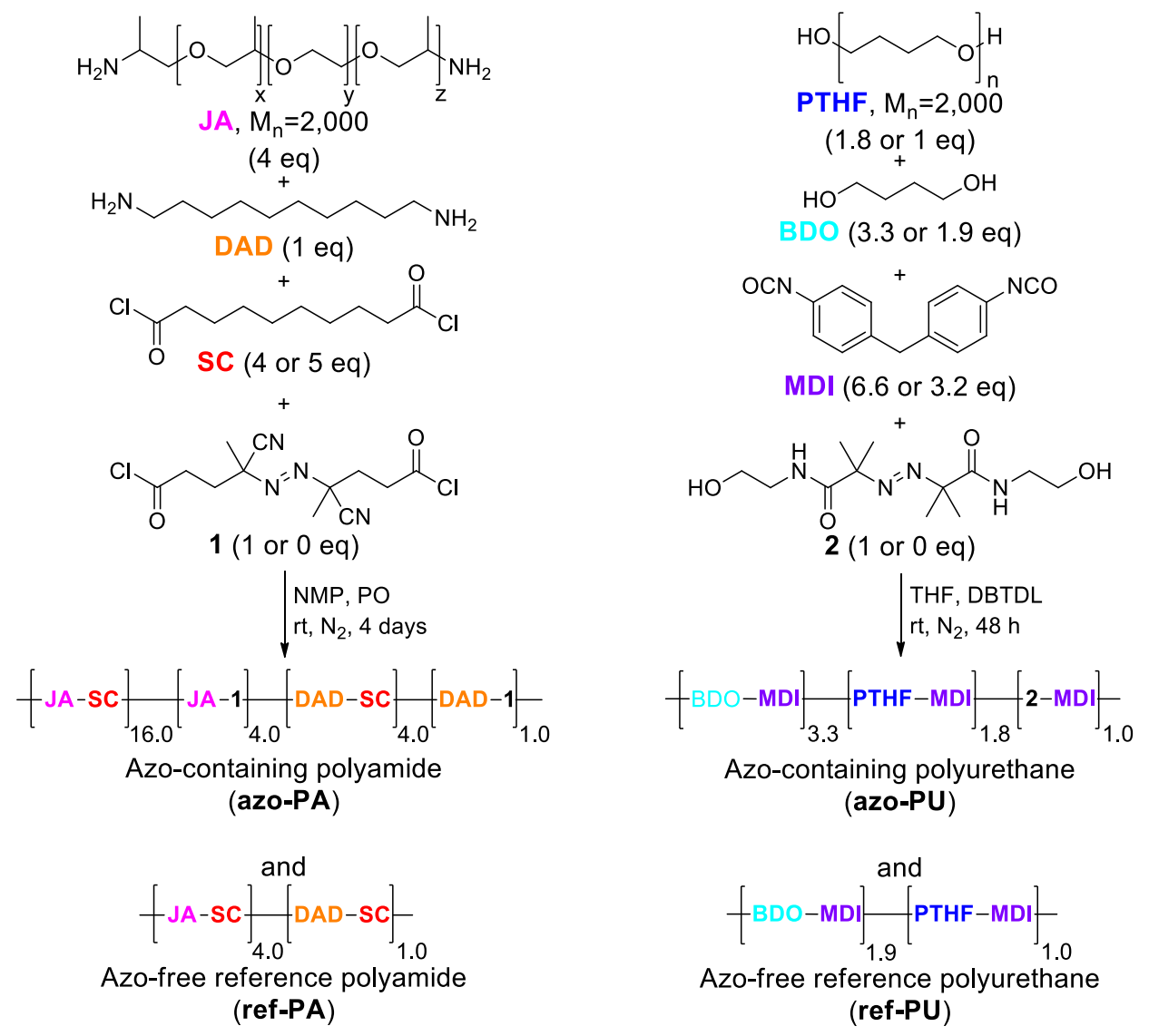

The polyamides azo-PA and ref-PA were synthesized by the low-temperature solution polycondensation reaction of DAD, JA $\left(M_{\mathrm{n}}=2,000 \mathrm{~g} / \mathrm{mol}\right), \mathrm{SC}$ and (in the case of the azo-PA) 1 in NMP (Scheme 1a). ${ }^{31}$ Propylene oxide was used to neutralize the $\mathrm{HCl}$ released during the polycondensation, giving easily removable volatiles, ${ }^{32}$ and an equimolar ratio of hard and soft segments was used. The polyurethanes azo-PU and ref-PU were synthesized using an established protocol ${ }^{33}$ by reacting MDI with BDO, PTHF $\left(M_{\mathrm{n}}=2,000 \mathrm{~g} / \mathrm{mol}\right)$ and (in the case of the azo-PU) 2 in THF, using dibutyltin dilaurate (DBTDL) as catalyst (Scheme 1b); a slight excess of MDI ( $\mathrm{NCO} / \mathrm{OH}$ ratio of 1.10$)$ was necessary to obtain polymers with satisfactory molecular weight. All polymers made were recovered by precipitation and filtration and were 
characterized to satisfaction by FT-IR, ${ }^{1} \mathrm{H}$ and ${ }^{13} \mathrm{C}$ NMR spectroscopy and elemental analysis (Supporting Information, Figures S1-S18). The molecular weights, determined by size exclusion

Table 1. General parameters of the azo-containing polyamide and polyurethane (azo-PA and azo-PU) and the corresponding azo-free control polymers (ref-PA, ref-PU) synthesized.

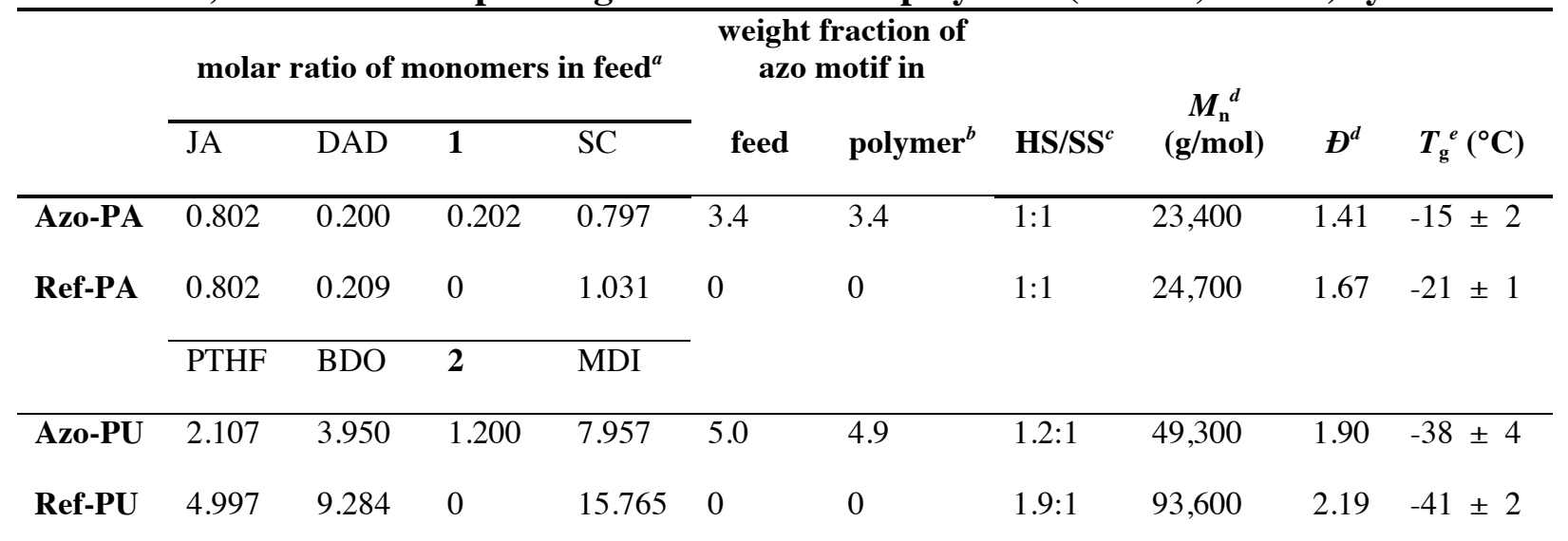

${ }^{a} \mathrm{JA}=\mathrm{Jeffamine} ; \mathrm{DAD}=$ diaminodecane; $\mathrm{SC}=$ sebacoyl chloride; $\mathrm{PTHF}=$ poly(tetrahydrofuran); $\mathrm{BDO}=$ butanediol; MDI=4,4'-methylenebis(phenyl isocyanate). ${ }^{b}$ Determined by ${ }^{1} \mathrm{H}$ NMR spectroscopy. ${ }^{c}$ Molar ratio of hard and soft segments. ${ }^{d}$ Number-average molecular weight and dispersity, determined by size exclusion chromatography (SEC). ${ }^{e}$ Determined by dynamic mechanical analysis (DMA).

chromatography (SEC), and the reactions parameters are compiled in Table 1. Gratifyingly, both azo-motif-containing polymers have appreciable $M_{\mathrm{n}}$ values (ca. 23,400 g/mol in the case of the azo-PA and 49,300 g/mol in the case of the azo-PU) and typical dispersity values $Ð$ (ca. 1.5 in the case of the PAs and ca. 2 in the case of the PUs). By and large, the data of the azo-free reference polymers are comparable to those of the azo-containing polymers, although in the case of the ref-PU a significantly higher $M_{\mathrm{n}}$ value was observed. A comparison of the ${ }^{1} \mathrm{H}$ NMR signals associated with the methyl protons of the residues of $\mathbf{1}(1.69 \mathrm{ppm})$ and $\mathbf{2}(1.33 \mathrm{ppm})$ (Supporting Information, Figures S3 and S11, Table 1) and methylene protons of the residues of DAD (3.22 ppm, alpha to carbonyl) and MDI (3.82), respectively, reveals that the concentrations of the azo-containing moieties in the polymers are comparable to those in the monomer feeds. This result is further confirmed by elemental analyses, which reveal higher nitrogen contents for 
the azo-containing polymers in comparison to the azo-free reference materials (Supporting Information). Thus, all analytical data confirm the successful outcome of the polymerization reactions, the absence of any adverse effects associated with the azo motifs, and the quantitative integration of the azo-motifs into the polymer backbones.

\section{Thermal and mechanical properties}

Thermogravimetric analyses (TGA) reveal that a thermal window in which the azo motifs are stable is available below ca. $90{ }^{\circ} \mathrm{C}$ for the azo-PA and $120{ }^{\circ} \mathrm{C}$ for the azo-PU for the processing of the polymers (Figures 1a and 2a), although we note that these limiting temperatures depend on the heating rate. Above these thresholds, both TGA traces display a step-wise weight loss that is not seen in the TGA traces of the corresponding azo-free reference polymers (Supporting Information, Figures S19 and S20) and appears to indicate the loss of $\mathrm{N}_{2}$ upon decomposition (Figures 1a and $2 \mathrm{a}$ ). Indeed, a weight reduction of the order of $1 \%$ matches the weight reduction expected from the loss of all $\mathrm{N}_{2}$ contained in azo-PA and azo-PU, i.e. the $\mathrm{N}=\mathrm{N}$ motif corresponding to ca. $10 \mathrm{wt} \%$ of the azo compounds $\mathbf{1}$ and $\mathbf{2}$. However, the thermal degradation profiles are not clearcut "steps"; in both cases the TGA traces have a slightly negative slope, indicating further decomposition, until significant rate changes at ca. $350{ }^{\circ} \mathrm{C}$ (azo-PA) and $250{ }^{\circ} \mathrm{C}$ and $300{ }^{\circ} \mathrm{C}$ (azoPU) reveal decomposition processes that are also seen in the TGA traces of the azo-free reference polymers (Supporting Information, Figures S19 and S20).

The differential scanning calorimetry (DSC) first heating trace of azo-PA shows a sharp endothermic transition at $37^{\circ} \mathrm{C}$, which is associated with the melting of the crystalline fraction, and a broad exothermic transition that stretches from 100 to $150{ }^{\circ} \mathrm{C}$, which is neither present in the second heating scan nor in the DSC traces of ref-PA and thus appears to reflect the decomposition of the azo motif (Figure 1b, Supporting Information, Figures S21a and S22a). 

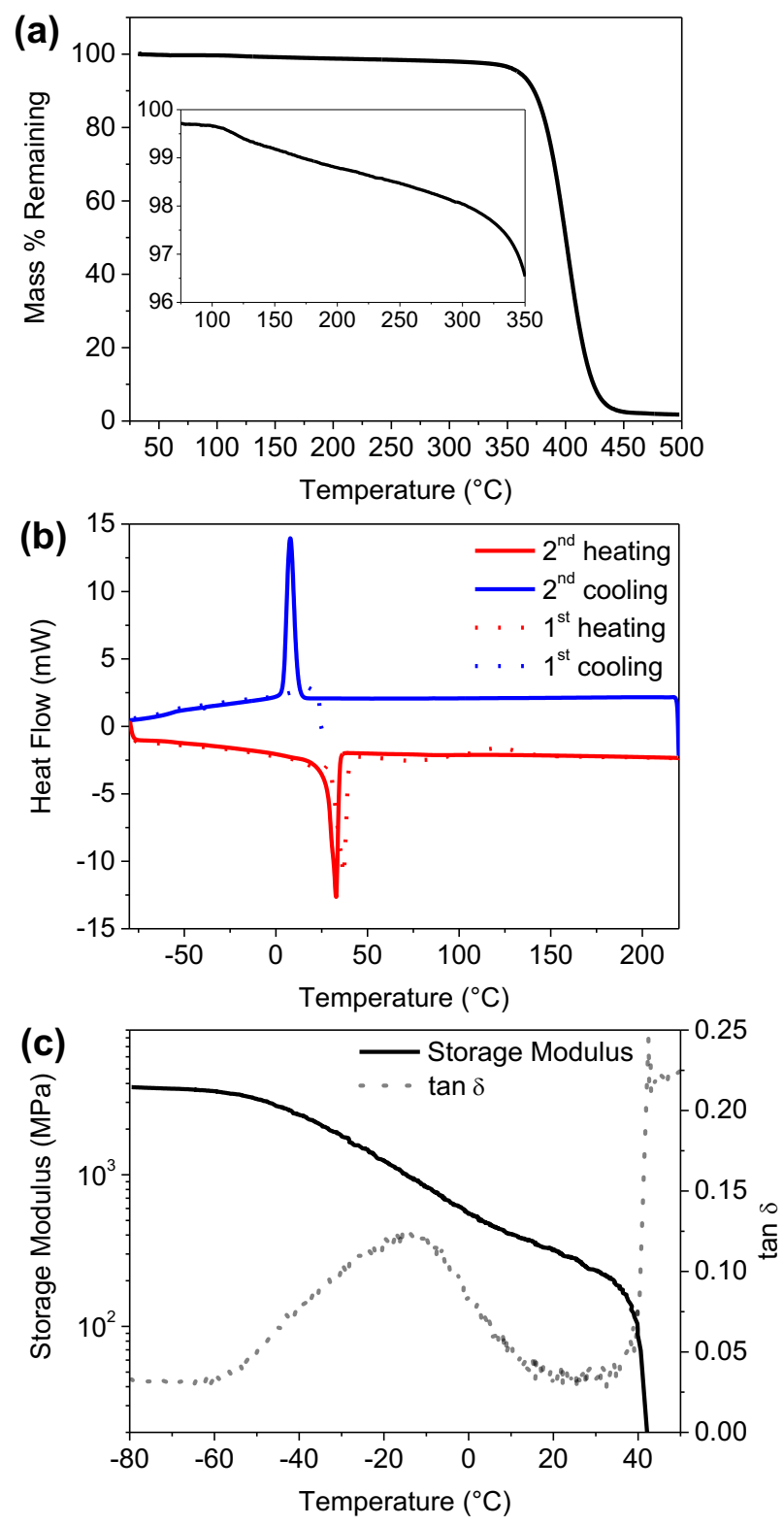

Figure 1. Thermal and thermomechanical properties of the azo-containing polyamide (azo-PA). (a) Thermogravimetric analysis (TGA) trace. (b) Differential scanning calorimetry (DSC) trace. (c) Dynamic mechanical analysis (DMA) data. All experiments were conducted under $\mathrm{N}_{2}$ at heating/cooling rates of $10{ }^{\circ} \mathrm{C} / \mathrm{min}$ (TGA, DSC) or $3{ }^{\circ} \mathrm{C} / \mathrm{min}$ (DMA). 

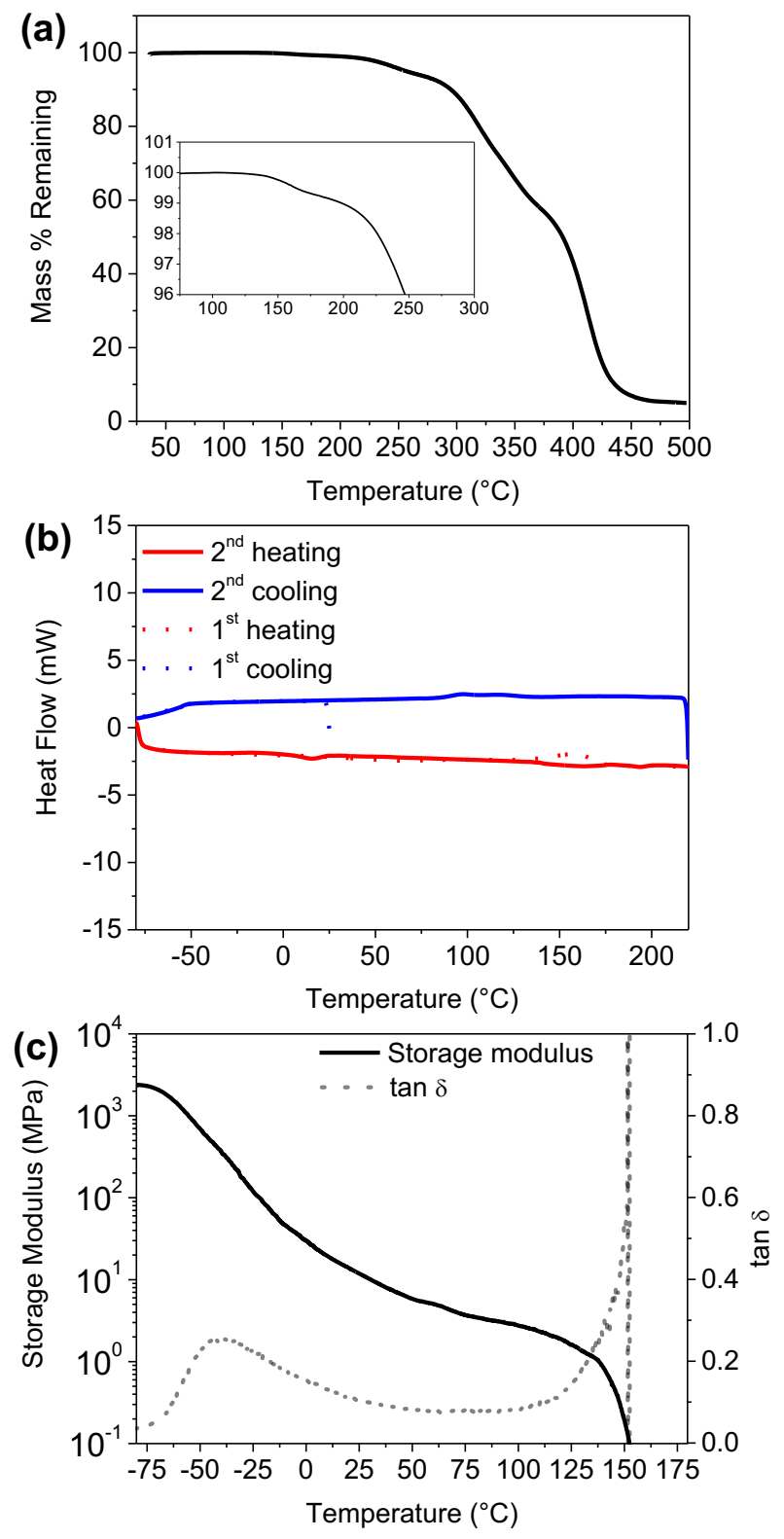

Figure 2. Thermal and thermomechanical properties of the azo-containing polyurethane (azoPU). (a) Thermogravimetric analysis (TGA) trace. (b) Differential scanning calorimetry (DSC) trace. (c) Dynamic mechanical analysis (DMA) data. All experiments were conducted under $\mathrm{N}_{2}$ at heating/cooling rates of $10^{\circ} \mathrm{C} / \mathrm{min}$ (TGA, DSC) or $3{ }^{\circ} \mathrm{C} / \mathrm{min}$ (DMA). 
Cooling and second heating traces of the azo-PA show exclusively sharp peaks around $9{ }^{\circ} \mathrm{C}$ (cooling, exothermic) and $33{ }^{\circ} \mathrm{C}$ (heating, endothermic) related to the crystallization and melting. The melting temperature $\left(T_{\mathrm{m}}\right)$ recorded upon second heating of azo-PA is slightly lower than the one observed for the pristine material, but it matches the values observed for the ref-PA (first and second heating) and azo-PA that had been heated to $60{ }^{\circ} \mathrm{C}$ only (Supporting Information, Figure S21b and 22b). In summary, the DSC data reveal the semicrystalline nature of the PAs, show that the melting temperature of the crystalline portion is slightly reduced upon decomposition of the azo motif, and that such decomposition can be suppressed if the temperature is kept below ca. $60{ }^{\circ} \mathrm{C}$.

The DSC first heating trace of the azo-PU displays only a weak, irreversible, broad exothermic transition between 140 and $170{ }^{\circ} \mathrm{C}$ that is absent in the second heating scan and the DSC traces of the ref-PU and thus interpreted as dissociation of the azo motif, whereas the second heating scans - and in the case of the ref-PU also the first heating scan - shows only a weak exothermic transition around $175{ }^{\circ} \mathrm{C}$, that reflects the melting of the PU's hard segments (Figure $2 \mathrm{~b}$, Supporting Information, Figures S23 and S24).

Dynamic mechanical analyses (DMA) were carried out to gain an overview of the thermomechanical properties of the polymers studied. The DMA traces of azo-PA and ref-PA are virtually identical; they reveal a rigid regime with a tensile storage modulus ( $\left.E^{\prime}\right)$ of ca. $3.7 \mathrm{GPa}$ below $-60{ }^{\circ} \mathrm{C}$, an extremely broad glass transition that extends from -55 to $20^{\circ} \mathrm{C}$ and features a maximum at $-15{ }^{\circ} \mathrm{C}$ (azo-PA) and $-21{ }^{\circ} \mathrm{C}$ ref-PA (Figure 1c, Supporting Information, Figure S25). Both materials display a room-temperature $\left(25^{\circ} \mathrm{C}\right) E^{\prime}$ of ca. $250 \mathrm{MPa}$, and fail around 40 ${ }^{\circ} \mathrm{C}$, i.e., around the $T_{\mathrm{m}}$ established by DSC (vide supra). The DMA traces of azo-PU and ref-PU (Figure 2c, Supporting Information, Figure S26) show the typical features of a phase separated 
segmented polyurethane, with a $T_{\mathrm{g}}$ of $-41{ }^{\circ} \mathrm{C}$ and a rubbery plateau that extends up to the failure temperature of ca. $150{ }^{\circ} \mathrm{C}$ (azo-PU) and $180{ }^{\circ} \mathrm{C}$ (ref-PU). The $T_{\mathrm{g}}$ of the azo-PU is slightly broader than that of the ref-PU, and therefore the azo motif causes a slight increase of $E$ ' in the region between $T_{\mathrm{g}}$ and ca. $100{ }^{\circ} \mathrm{C}$, where $E$ ' drops below that of the ref-PU. The slanted nature of the rubbery plateau, the lower failure temperature of azo-PU vis a vis ref-PU, and the thermal data discussed above, suggest that the softening and mechanical failure of azo-PU at higher temperature is indeed related to the thermal dissociation of the azo motif. Overall the PAs are stiffer than the PUs, both in the glassy as well as in the rubbery state (Supporting Information, Figures S25 and S26). Both materials are rubbery at room temperature, but while the PUs presented a very high toughness (vide infra), it was impossible to perform any stress-strain measurement with the PAs, presumably due to their limited molecular weight.

\section{Controlled degradation of azo-containing polyamide}

The thermally induced decomposition behavior of azo-PA and ref-PA was first probed in solution. Thus, the polymers were dissolved at a concentration of $2.5 \mathrm{mg} / \mathrm{mL}$ under ambient conditions in either acetonitrile $(\mathrm{MeCN})$ or carbon tetrachloride $\left(\mathrm{CCl}_{4}\right)$, which were chosen with the objective to compare the dissociation behavior in solvents of inert nature $(\mathrm{MeCN})$ and high chain transfer constant $\left(\mathrm{CCl}_{4}\right){ }^{26}$ The solutions were rapidly heated to $140{ }^{\circ} \mathrm{C}$ (i.e., the decomposition temperature identified by TGA and DSC, vide supra) using pressure-resistant vials and a microwave synthesizer, maintained at this temperature for $5 \mathrm{~min}$, and then rapidly cooled to ambient temperature. Changes to the molecular weight and the dispersity were analyzed by SEC (Figure 3, Table 2). 

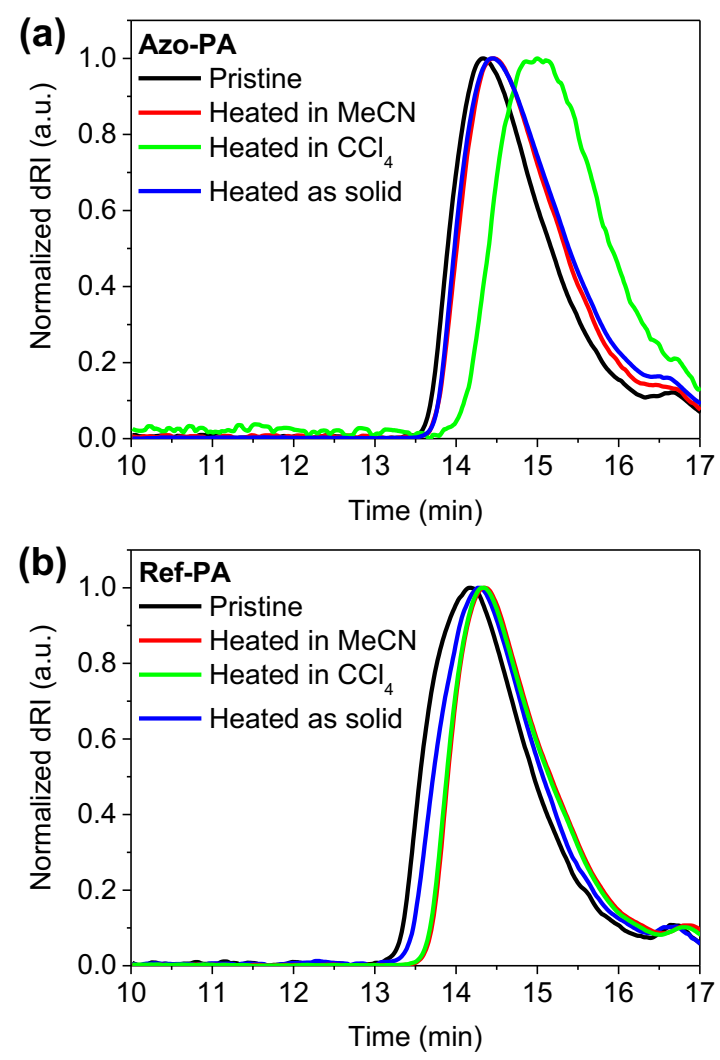

Figure 3. Size exclusion chromatography (SEC) traces of (a) the azo-containing polyamide azoPA and (b) the azo-free reference ref-PA in the pristine state (black lines), and after heat treatment $\left(5 \mathrm{~min}\right.$ at $\left.140{ }^{\circ} \mathrm{C}\right)$ of $2.5 \mathrm{mg} / \mathrm{mL}$ solutions in $\mathrm{MeCN}$ (red lines), $\mathrm{CCl}_{4}$ (green lines) or in the solid state (blue lines).

Interestingly, in MeCN, only a minor reduction of $M_{\mathrm{n}}$ was observed by SEC for both azo-PA and ref-PA (Figure 3, Table 2), which we interpret as the result of unspecific thermal degradation, perhaps hydrolysis of the amide groups by trace amounts of water present. In the case of azo-PA, the azo motifs are certainly cleaved by the treatment as confirmed by the abovediscussed thermal data, but the SEC data suggest that the macroradicals formed instantly recombine after $\mathrm{N}_{2}$ release, so that the molecular weight is not reduced. This behavior was already reported by Moore and coworkers for a poly(ethylene glycol) comprising the same azo 
motif used here in the center of the polymer chain, upon thermal treatment in the same solvent. ${ }^{25}$ Speculating that such recombination could be stifled by way of radical transfer to the solvent, the thermal degradation experiment was repeated, but $\mathrm{CCl}_{4}$ was employed as the solvent. While the behavior of the azo-free ref-PA remained, as expected, unchanged, a pronounced reduction of $M_{\mathrm{n}}$ from 23,400 to $11,200 \mathrm{~g} / \mathrm{mol}$ was observed in the case of the azo-PA, as a result of the thermally induced cleavage of the azo motif and abstraction of the radicals from the polymer fragments. Thus, conducting the thermally induced degradation in the presence of a chain transfer agent has a significant influence on the fate of the polymer radicals formed in the process, and permits suppressing their instant recombination. Generally, $\varnothing$ increased only slightly, except in $\mathrm{CCl}_{4}$, where an increase from 1.41 to 1.96 was observed.

Table 2. Molecular weights of azo-PA and ref-PA in their pristine state and after heating under different conditions.

\begin{tabular}{lcccccc}
\hline & \multicolumn{3}{c}{ Azo-PA } & \multicolumn{3}{c}{ Ref-PA } \\
\cline { 2 - 7 } & $\begin{array}{c}M_{\mathrm{n}}{ }^{\mathrm{a}} \\
(\mathrm{g} / \mathrm{mol})\end{array}$ & $\begin{array}{c}M_{\mathrm{w}}{ }^{\mathrm{a}} \\
(\mathrm{g} / \mathrm{mol})\end{array}$ & $\bigoplus^{\mathrm{a}}$ & $\begin{array}{c}M_{\mathrm{n}}{ }^{\mathrm{a}} \\
(\mathrm{g} / \mathrm{mol})\end{array}$ & $\begin{array}{c}M_{\mathrm{w}}{ }^{\mathrm{a}} \\
(\mathrm{g} / \mathrm{mol})\end{array}$ & $\bigoplus^{\mathrm{a}}$ \\
\hline Pristine & 23,400 & 33,000 & 1.41 & 24,700 & 41,300 & 1.67 \\
Heated in MeCN & 18,900 & 31,100 & 1.65 & 19,600 & 29,500 & 1.51 \\
Heated in CCl & 11,200 & 21,900 & 1.96 & 20,000 & 30,000 & 1.50 \\
Heated in solid state & 20,100 & 30,000 & 1.49 & 21,800 & 35,300 & 1.62
\end{tabular}

${ }^{a}$ Determined by size exclusion chromatography (SEC). The samples were dried before they were heated for $5 \mathrm{~min}$ at $140{ }^{\circ} \mathrm{C}$ in acetonitrile $(\mathrm{MeCN})$, tetrachloromethane $\left(\mathrm{CCl}_{4}\right)$, or the solid state. The concentration of the polymers in the solutions was $2.5 \mathrm{mg} / \mathrm{mL}$.

We also explored the thermal degradation of azo-PA and ref-PA in the solid state $\left(140^{\circ} \mathrm{C}\right.$ for $5 \mathrm{~min}$ ), but not surprisingly the results (Figure 3, Table 2) mirror the behavior observed for the $\mathrm{MeCN}$ solution. To confirm that the thermal treatment in absence of a chain transfer agent (i.e. in 
MeCN solution and in the solid state) indeed triggered decomposition of the azo motif under $\mathrm{N}_{2}$ release and recombination of the resulting radicals, we compared the ${ }^{1} \mathrm{H}$ NMR spectra of heated (in the solid state at $140{ }^{\circ} \mathrm{C}$ for $5 \mathrm{~min}$ and then dissolved in $\mathrm{CDCl}_{3}$ ) and pristine samples (Supporting Information, Figure S5a, b), and observed changes in the characteristic signals of the methylene and methyl groups introduced by the azo moiety, i.e. around 2.46-2.25 (m, 4H, $\mathrm{CH}_{2}$, obstructed) and $1.70 \mathrm{ppm}\left(\mathrm{d}, 6 \mathrm{H}, \mathrm{CH}_{3}\right)$. Furthermore, elemental analyses showed a significant reduction of the nitrogen content after heating $\left(140{ }^{\circ} \mathrm{C}\right.$ for $\left.5 \mathrm{~min}\right)$ the azo-PA in solid state (Supporting Information). Thus, the thermally induced degradation of azo-PA strongly depends on and can be controlled by the nature of the environment; while heating invariably triggers the release of $\mathrm{N}_{2}$, the choice of the immediate environment is crucial, as recombination effects can be moderated via chain transfer to the latter. We speculate that a similar mechanism can also be exploited in the solid state, although this was not further probed in the present study.

\section{Controlled degradation of azo-containing polyurethane}

Since neither azo-PU nor ref-PU are soluble in $\mathrm{MeCN}$ or $\mathrm{CCl}_{4}$, the thermal degradation of these polymers was studied in tetrahydrofuran (THF) using pressure-withstanding vials and a microwave synthesizer. Based on the TGA and DSC data samples were heated to $150{ }^{\circ} \mathrm{C}$ for 5 min, but otherwise the same conditions as used for the PAs were applied. While the molecular weight of ref-PU was not affected at all by this treatment (Figure 4, Table 3), the $M_{\mathrm{n}}$ of the azoPU was reduced from 49,300 to $23,100 \mathrm{~g} / \mathrm{mol}$, indicating the cleavage of the azo motifs and the

absence of substantial recombination of the macroradicals formed. An even more pronounced reduction to $16,400 \mathrm{~g} / \mathrm{mol}$ was observed when azo-PU was heated in the solid state. Other conditions (temperature, time) were explored for both solution and solid state studies (Suppor- 
ting Information, Figures S27 and S29) and the results indicate that treatment at $150{ }^{\circ} \mathrm{C}$ for $5 \mathrm{~min}$ is an effective treatment for the decomposition of azo-PU. Heating the azo-PU at $160{ }^{\circ} \mathrm{C}$ for 5
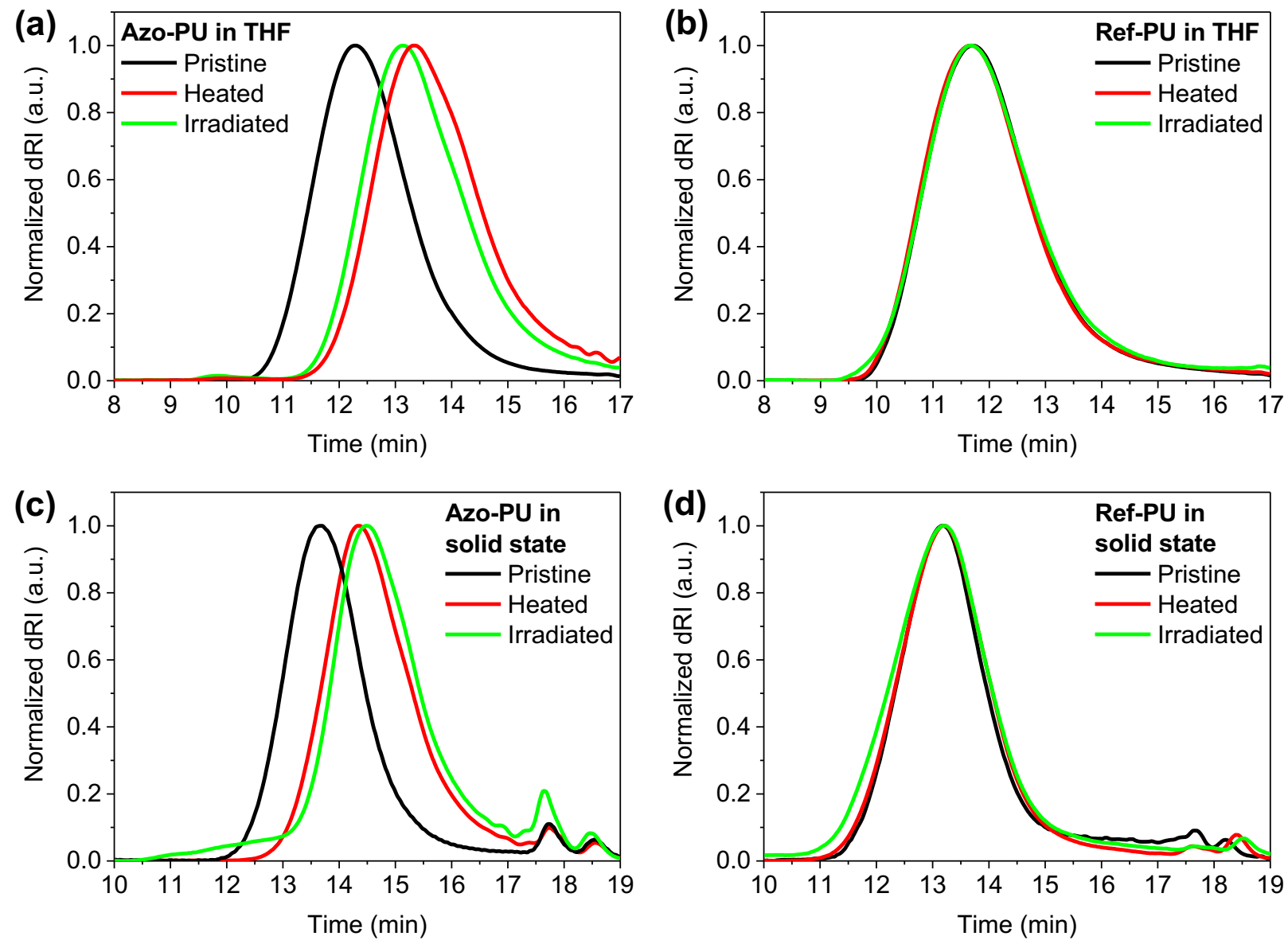

Figure 4. Size exclusion chromatography (SEC) traces of $(a, c)$ the azo-containing polyurethane azo-PU and (b, d) the azo-free reference ref-PU in the pristine state (black lines) and after heat treatment $\left(5 \mathrm{~min}\right.$ at $150{ }^{\circ} \mathrm{C}$, red lines) or exposure to UV light $\left(320-390 \mathrm{~nm}, 600 \mathrm{~mW} / \mathrm{cm}^{2}\right.$, green lines) in (a,b) THF solution $(2.5 \mathrm{mg} / \mathrm{mL}, 15 \mathrm{sec})$ or $(\mathrm{c}, \mathrm{d})$ the solid state $(30 \mathrm{sec})$.

min gave lower $M_{\mathrm{n}}$ in solution but the decomposition was fast enough in solid state that bubbles stayed trapped within the material because $\mathrm{N}_{2}$ formed very rapidly. These results reflect that the degradation of the azo-PU is less substantially moderated by the environment than that of the azo-PA studied here. Indeed, the specific azo motif employed in the azo-PA, featuring methyl, 
nitrile, and methylene groups $\alpha$ to the $\mathrm{N}_{2}$ bridge, decomposes under formation of radicals that are substantially less reactive than those formed by decomposition of the motif used in azo-PU, where stabilization is provided only through an amide and two methyl groups. ${ }^{27,28}$ Experimental evidence has been provided by photolysis reactions of model azo compounds that revealed a higher quantum efficiency for a molecule similar to 2 than for an analogous of $1 .^{29}$ The slightly lower $M_{\mathrm{n}}$ value observed when azo-PU was heated in the solid state (vis a vis the THF solution) seems to indicate that more radical recombinations occur in solution than in the solid state (vide infra), possibly because the lower translational mobility in the latter facilitates proton abstraction, which is less favored in solution.

Table 3. Molecular weights of azo-PU and ref-PU in their pristine state and after heating or exposure to UV light.

\begin{tabular}{lcc}
\hline & \multicolumn{2}{c}{$\boldsymbol{M}_{\mathrm{n}}{ }^{a}(\mathrm{~g} / \mathrm{mol})$} \\
\cline { 2 - 3 } & $\mathbf{A z o}-\mathrm{PU}$ & Ref-PU \\
\hline Pristine & 49,300 & 93,600 \\
Heated in THF & 23,100 & 94,400 \\
Irradiated in THF & 23,700 & 95,400 \\
Heated in the solid state & 16,400 & 91,800 \\
Irradiated in the solid state & 15,200 & 93,400
\end{tabular}

${ }^{a}$ Determined by size exclusion chromatography (SEC). All samples were dried before any treatment (heating for $5 \mathrm{~min}$ at $150{ }^{\circ} \mathrm{C}$ or exposure to UV light at $600 \mathrm{~mW} / \mathrm{cm}^{2}$ for $15 \mathrm{sec}$ in solution and $30 \mathrm{sec}$ in the solid state). The concentration of the polymers in THF was $2.5 \mathrm{mg} / \mathrm{mL}$.

As mentioned above, many azo compounds not only function as thermal initiators, but can also be used as photoinitiators, ${ }^{27}$ as they display an optical absorption band in the visible or the UV A 
range that permits optical excitation with readily accessible light sources. Indeed, this mechanism has been reported for 2,2'-azobis[2-methyl-N-(2-hydroxyethyl)propionamide] (2), ${ }^{34,35}$ which displays an absorption band that stretches from 420 to $300 \mathrm{~nm}$ and displays a maximum around $370 \mathrm{~nm}$ (in water, 0.028 M, Supporting Information, Figure S32). We speculated that this characteristic could be exploited for the controlled degradation of azo-PU using UV or visible light. Despite the low content of the azo-moiety and the low extinction coefficient of the monomer $2\left(12.32 \mathrm{~L} \cdot \mathrm{mol}^{-1} \cdot \mathrm{cm}^{-1}\right)$, the absorption spectrum of azo-PU clearly shows the characteristic shoulder associated with this motif (Supporting Information, Figure S35). Dilute $(2.5 \mathrm{mg} / \mathrm{mL})$ solutions of the two PUs in THF were exposed to UV light using a high power lamp (320-390 nm, $\left.600 \mathrm{~mW} / \mathrm{cm}^{2}, 15 \mathrm{sec}\right)$ under stirring. Gratifyingly, SEC analysis indicates that the effects of the irradiation are virtually identical to those observed upon heating: while the molecular weight of the ref-PU remained unchanged, the $M_{\mathrm{n}}$ of the azo-PU was reduced from 49,300 to $23,700 \mathrm{~g} / \mathrm{mol}$. Variation of the excitation time between 7.5 and $60 \mathrm{sec}$ (Supporting Information, Figure S33) shows that the light-induced dissociation is (under the conditions employed here) indeed complete in as little as $15 \mathrm{sec}$. The optically induced molecular weight reduction of azo-PU was comparable when the experiment was conducted in THF solution containing 5 drops of $\mathrm{CCl}_{4}$ (Supporting Information, Figure S33), suggesting that the presence of an auxiliary chain transfer agent is not needed to suppress dimerization of the macroradicals formed.

One of the attractive features of using light as a stimulus is that it can readily be applied, if desired also in a spatially resolved fashion, to solid specimens. Thus, films of the two polyurethanes were irradiated with UV light $\left(320-390 \mathrm{~nm}, 600 \mathrm{~mW} / \mathrm{cm}^{2}\right.$ for $\left.30 \mathrm{sec}\right)$ and SEC analyses were subsequently performed (Figure $4 \mathrm{c}$ and $\mathrm{d}$, Table 3). Note that the absorption associated 
with the azo-motif is small and it decreases upon UV exposure so that cleavage is likely to be homogeneous throughout the sample (Supporting Information, Figure S35). Also in this case, the molecular weight of ref-PU was not affected by the treatment with UV light, whereas the $M_{\mathrm{n}}$ of the azo-PU was reduced from 49,300 to $15,200 \mathrm{~g} / \mathrm{mol}$. As in the case of the thermal treatment of the azo-PU, the molecular weight reduction was slightly more pronounced in the solid state than in solution, suggesting that more recombination of the macroradicals may occur in the latter (vide supra). We also subjected the azo-PA to UV light irradiation, but as expected on the basis of the results obtained after thermal treatment (vide supra), the molecular weight did not decrease (Supporting Information, Figures S41 and S42).

Although the UV-Vis spectra of $\mathbf{2}$ and the azo-PU (Supporting Information, Figures S32 and S35) show only little absorption above $400 \mathrm{~nm}$, we explored the response of thin films upon irradiation with visible light in the range of $390-500 \mathrm{~nm}$ using the same lamp at the same power density $\left(600 \mathrm{~mW} / \mathrm{cm}^{2}\right)$. Also, in this case, a $M_{\mathrm{n}}$ decrease was observed for the azo-PU while the ref-PU was not altered (Supporting Information, Figures S47-S51). Even if a slightly longer (60 vs. $30 \mathrm{sec}$ ) irradiation time was required to reach a similar $M_{\mathrm{n}}$ as afforded by exposure to UV light, the azo-PU is clearly responsive to short-wavelength visible light. An IR camera was used to monitor the temperature of the films during the light irradiation processes, and the temperature-time diagrams (Supporting Information, Figures S38, S40, S49 and S51) reveal only a very small temperature increase (ca. $10{ }^{\circ} \mathrm{C}$ and $3{ }^{\circ} \mathrm{C}$ upon exposure to $\mathrm{UV}$ and visible light, respectively), indicating that the process is purely optically engendered. Only a minor increase of $Ð$ was observed in all cases, unless the samples were heated or irradiated with UV light for longer periods. 
In the case of the azo-PU, a comparison of the $M_{\mathrm{n}}$ values before $(49,300 \mathrm{~g} / \mathrm{mol})$ and after $(15,700-30,900 \mathrm{~g} / \mathrm{mol})$ optical or thermal treatment in the solid state and the average number of azo moieties incorporated into the polymer backbone (8-9) suggests that not all azo motifs lead to chain cleavage. Assuming a statistical incorporation of the azo moieties and $100 \%$ cleavage, the theoretical $M_{\mathrm{n}}$ value that should be obtained after complete cleavage would be ca. 5,800 g/mol. To investigate this discrepancy, an ${ }^{1} \mathrm{H}$ NMR study was conducted. The characteristic signals of pristine and heated (solid state, $150{ }^{\circ} \mathrm{C}$ for $5 \mathrm{~min}$ ) azo-PU samples were monitored and compared. An analysis of these signals reveals that: (i) a portion of the azo moieties dissociated and caused cleavage of the backbone, (ii) another portion of the azo moieties dissociated but the radicals recombined, and (iii) a portion of the azo moieties did not react. The diagnostic signals that were monitored include a singlet at $1.33 \mathrm{ppm}$ corresponding to methyl protons of the azo moiety in the pristine material (Supporting Information, Figures S13a, c), a septet at $2.27 \mathrm{ppm}$, in the heated material, which is interpreted as a proton $\alpha$ to the two methyl groups, meaning that proton abstraction occurred. This is supported by the presence of a coupling partner at $1.05 \mathrm{ppm}$ (doublet, methyl protons). Also, a singlet at $1.18 \mathrm{ppm}$ in the heated material corresponds to the methyl groups of the recombined species. Analysis of the related integrals suggests that heating of $5 \mathrm{~min}$ at $150{ }^{\circ} \mathrm{C}$ affords approximate $37 \%$ of the cleaved product and $28 \%$ of the recombined species, whereas $35 \%$ of the azo motifs remain intact. These results correlate with the calculated assumption that 8-9 azo moieties are present per chain (vide supra) and explain the ca. threefold $M_{\mathrm{n}}$ reduction observed after treatment. In the case of a longer heating (solid state, $150{ }^{\circ} \mathrm{C}$ for 30 min), the signal at $1.33 \mathrm{ppm}$ completely disappeared, meaning that all azo moieties decomposed and the radicals either reacted or recombined (Supporting Information, Figures S13b, c). The ratio between the integrals of the reacted $(1.05 \mathrm{ppm})$ and recombined $(1.18 \mathrm{ppm})$ species 
remained the same at ca. 1.3-1.4. As a result of the complete decomposition of the azo motifs, the $M_{\mathrm{n}}$ decrease was slightly more pronounced (Supporting Information, Figure S31). Moreover, this observation confirms that the complete $\mathrm{N}_{2}$ release, as exposed by TGA, i.e. ca. $1 \mathrm{wt} \%$ (vide supra), can also be reached by applying an appropriate short treatment. The ${ }^{1} \mathrm{H}$ NMR spectra of the pristine and heated (solid state, $150{ }^{\circ} \mathrm{C}$ for $5 \mathrm{~min}$ ) ref-PU were identical and therefore support the absence of any degradation (Supporting Information, Figures S15-S18).
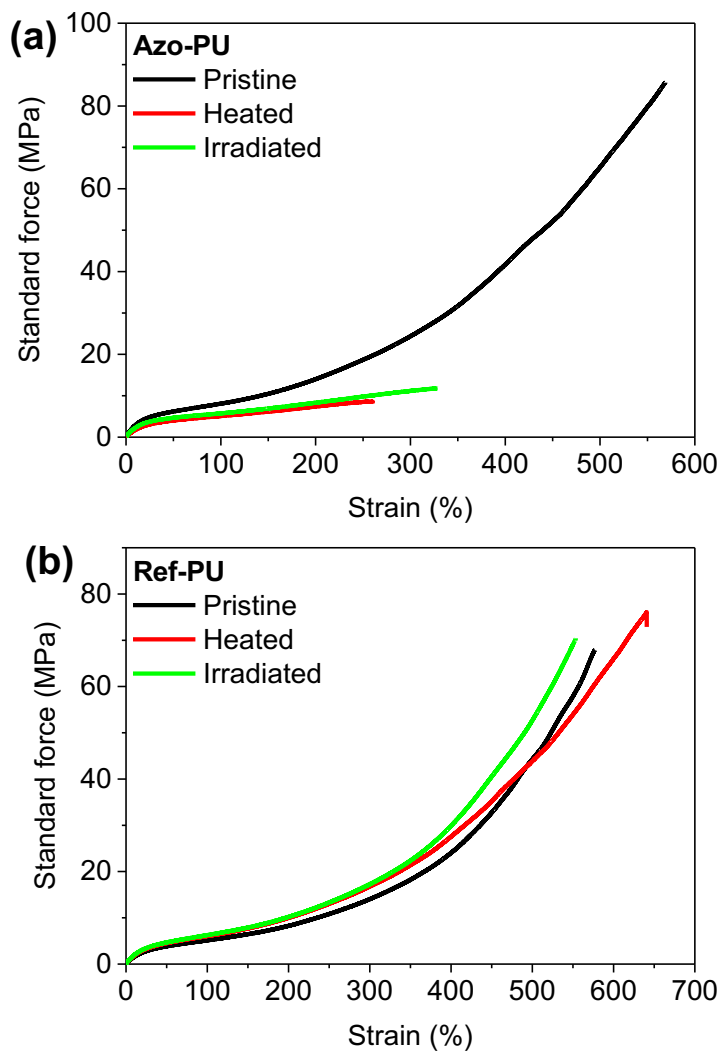

Figure 5. Representative stress-strain curves of films of the (a) azo-containing azo-PU and (b) the azo-free reference ref-PU in the pristine state (black lines), and after heat treatment (5 min at $150{ }^{\circ} \mathrm{C}$, red lines) or exposure to UV light $\left(320-390 \mathrm{~nm}, 600 \mathrm{~mW} / \mathrm{cm}^{2}, 30 \mathrm{sec}\right.$, green lines). The film thickness was in all cases $120 \mu \mathrm{m}$. 
Assuming that the significant $M_{\mathrm{n}}$ decrease induced by heat and exposure to UV light would exert a significant influence on the material mechanical properties of the azo-PU, stress-strain measurements of pristine and heat or light-treated azo-PU and ref-PU were performed (Figure 5). The heat treatment was applied prior to cutting whereas the light irradiation was locally performed after, and limited to the central part of the specimen (Supporting Information, Figure S43a). The light irradiation had no influence on the visual appearance of the sample (Supporting Information, Figure S43b) and on its thickness (i.e. $120 \mu \mathrm{m}$ ). Again, temperature-time diagrams were recorded to confirm that the temperature increase was negligible (Supporting Information, Figures S44-S45). The mechanical properties of the pristine, heat-treated, and light-treated refPU samples are virtually identical (Figure 5b); the stress-strain curves are characteristic of a phase-segregated thermoplastic elastomer, with an elongation at break $\left(\varepsilon_{\mathrm{R}}\right)$ between $563 \pm 18$ and $606 \pm 70 \%$ and a stress at break $\left(\sigma_{R}\right)$ of $64 \pm 19-75 \pm 5 \mathrm{MPa}$ (Supporting Information, Table S46). The characteristics of the pristine azo-PU are also similar, with a $\varepsilon_{R}$ of $556 \pm 25 \%$ and a $\sigma_{R}$ of $81 \pm 9 \mathrm{MPa}$. By contrast, the heated and UV-exposed specimens showed a substantial reduction of $\varepsilon_{R}$ to $270 \pm 35 \%$ and $333 \pm 6 \%$, respectively, and of $\sigma_{R}$ to $9 \pm 1 \mathrm{MPa}$ and $13 \pm 1$ $\mathrm{MPa}$, respectively. Thus, while the mechanical properties are significantly changed, the degraded materials retain mechanical integrity and are merely weakened. This is confirmed by analyzing the Young's modulus $(E)$ values, which in the case of the azo-PU were reduced from $41 \pm 1$ $\mathrm{MPa}$ (pristine) to $24 \pm 1 \mathrm{MPa}$ upon heating and $35 \pm 1 \mathrm{MPa}$ upon light-treatment (Supporting Information, Table S46). The ref-PU has a slightly a lower stiffness than the azo-PU, as was shown by DMA (vide supra), and its $E$ hardly changed from $19 \pm 1 \mathrm{MPa}$ upon heating (to $22 \pm 1$ $\mathrm{MPa})$ or UV light treatment $(24 \pm 1 \mathrm{MPa})$. The fact that that the irradiated samples exhibited slightly higher $\varepsilon_{\mathrm{R}}, \sigma_{\mathrm{R}}$, and $E$ than the heated materials seem to contrast the fact that lower 
molecular weights were observed for the irradiated samples (vide supra) but the small difference may be related to the fact that the UV light was locally applied (on ca. $15 \mathrm{~mm}$ of the $30 \mathrm{~mm}$ of the measured part), whereas the heating was applied homogeneously to the entire specimens.

As mentioned above, one attractive feature of using light as a stimulus is that it can be applied locally and in a spatially resolved manner, for example by using a photomask that creates a specific pattern or gradient. This was explored by applying a simple mask that allowed degrading selected areas of a rectangular film of azo-PU upon exposure to UV light, while others were left in the pristine state (Figure 6, zones 2 and 4 were irradiated with 320-390 nm UV light at 600 $\mathrm{mW} / \mathrm{cm}^{2}$ for $30 \mathrm{sec}$ ). The images shown in Figure 6 show strikingly that such treatment permits the creation of objects with locally varying mechanical properties, in which mechanical deformation leads to inhomogeneous deformation. Indeed, the relative extension of the pristine zones ( 1 and 3$)$ is much less pronounced than that of the degraded zones ( 2 and 4$)$, which is in accordance with the different deformation behaviors established for the pristine and degraded azo-PU (Figure 5).

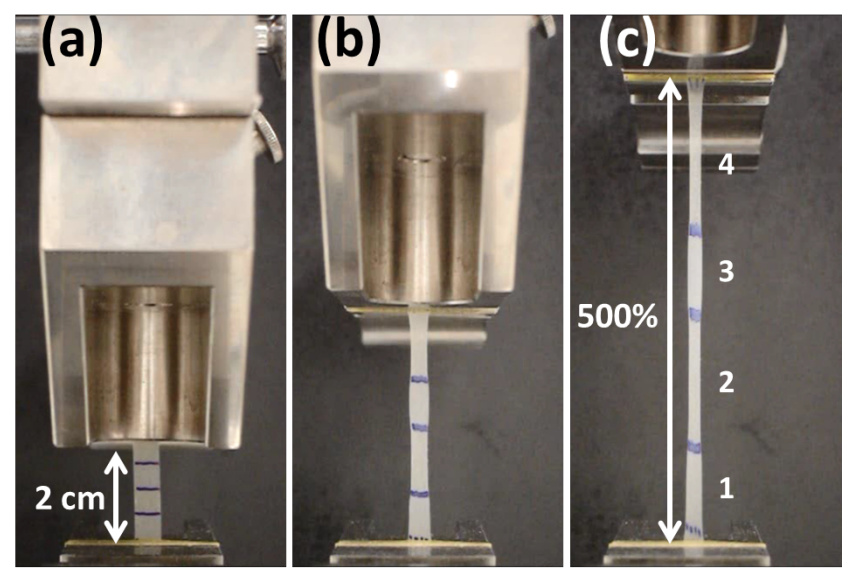

Figure 6. Images showing a photopatterned azo-PU film (a) before, (b) during, and (c) after being subjected to an overall elongation of 500\%. Zones 2 and 4 had been irradiated with 320- 
$390 \mathrm{~nm}$ UV light at $600 \mathrm{~mW} / \mathrm{cm}^{2}$ for $30 \mathrm{sec}$, whereas zones 1 and 3 had been covered with a photomask and remained unexposed.

\section{CONCLUSIONS}

In summary, we have shown that azo moieties can not only be used as radical polymerization initiators but also as thermally and optically addressable motifs that permit the design of polymers whose molecular weight can be reduced on demand. We presented here novel types of azo-containing polymers that were prepared via straightforward step-growth polymerization reactions; we focused on simple polyamides and polyurethanes, but of course the framework presented here is readily applicable to other polymers, provided that the reaction can be conducted at a sufficiently low temperature. Our systematic study revealed that the stimuliinduced degradation of the molecular weight is not only possible, but that it depends strongly on the nature of the polymer backbone, the state of matter, and, in solution, also on the nature of the solvent. Most of all is the azo moiety design of importance. Indeed, the more stable macroradicals formed in the case of the azo-containing polyamide (azo-PA) required the presence of a chain-transfer agent so that recombination be suppressed. This was shown in solution where $\mathrm{CCl}_{4}$ was used as solvent and in which dissolved azo-PA was rapidly heated and exposed a MW decrease. Moreover, the reactive radicals originating from the azo-containing polyurethane (azo-PU) exhibited the tendency to react further instead of recombining. We demonstrated that the thermal or optical treatment applied to the azo-PU can exert a significant influence on the material's mechanical properties, in the form of pronounced elongation and stress at break reductions. The controlled degradation of the polymer in well-defined areas can readily be achieved via photopatterning, and this approach was shown to be useful to produce 
solid structures with graded mechanical properties. We speculate that materials such as the ones presented here may be useful for debonding-on-demand adhesives, recyclable composite materials, and mechanically graded connectors. The concept should also be useful to create gels with programmable mechanical properties, which are useful to influence the development of cultured cells.

\section{ASSOCIATED CONTENT}

Supporting Information. A supporting information containing FT-IR, NMR, EA, DMA, TGA, DSC, SEC analyses and details about the heating and light irradiation experiments is available free of charge via the Internet at http://pubs.acs.org.

\section{AUTHOR INFORMATION}

\section{Corresponding Author}

*E-mail: christoph.weder@unifr.ch (C.W.).

\section{Notes}

The authors declare no competing financial interest.

\section{ACKNOWLEDGMENTS}

The authors thank Prof. Bernd Giese (University of Fribourg) for stimulating discussions. The authors acknowledge funding from the European Research Council (Grant ERC-2011-AdG 291490-MERESPO) and the Adolphe Merkle Foundation. This work was also partially 
supported by the National Center of Competence in Research (NCCR) Bio-Inspired Materials, a research instrument of the Swiss National Science Foundation.

\section{REFERENCES}

(1) Delplace, V.; Nicolas, J. Degradable vinyl polymers for biomedical applications. Nat. Chem. 2015, 7, 771-784.

(2) Heinzmann, C.; Weder, C.; de Espinosa, L. M. Supramolecular polymer adhesives: advanced materials inspired by nature. Chem. Soc. Rev. 2016, 45, 342-358.

(3) Huu, V. A. N.; Luo, J.; Zhu, J.; Zhu, J.; Patel, S.; Boone, A.; Mahmoud, E.; McFearin, C.; Olejniczak, J.; Lux, C. D.; Lux, J.; Fomina, N.; Huynh, M.; Zhang, K.; Almutairi, A. Light-responsive nanoparticle depot to control release of a small molecule angiogenesis inhibitor in the posterior segment of the eye. J. Controlled Release 2015, 203, 39-39.

(4) Mohapatra, H.; Kim, H.; Phillips, S. T. Stimuli-Responsive Polymer Film that Autonomously Translates a Molecular Detection Event into a Macroscopic Change in Its Optical Properties via a Continuous, Thiol-Mediated Self-Propagating Reaction. J. Am. Chem. Soc. 2015, 137, 12498-12501.

(5) Stuart, M. A. C.; Huck, W. T. S.; Genzer, J.; Muller, M.; Ober, C.; Stamm, M.; Sukhorukov, G. B.; Szleifer, I.; Tsukruk, V. V.; Urban, M.; Winnik, F.; Zauscher, S.; Luzinov, I.; Minko, S. Emerging applications of stimuli-responsive polymer materials. Nat. Mater. 2010, 9, 101-113.

(6) Roy, D.; Cambre, J. N.; Sumerlin, B. S. Future perspectives and recent advances in stimuliresponsive materials. Prog. Polym. Sci. 2010, 35, 278-301.

(7) Yoshida, T.; Lai, T. C.; Kwon, G. S.; Sako, K. pH- and ion-sensitive polymers for drug delivery. Expert Opinion on Drug Delivery 2013, 10, 1497-1513.

(8) Peterson, G. I.; Larsen, M. B.; Boydston, A. J. Controlled Depolymerization: StimuliResponsive Self-Immolative Polymers. Macromolecules 2012, 45, 7317-7328.

(9) Roy, D.; Brooks, W. L. A.; Sumerlin, B. S. New directions in thermoresponsive polymers. Chem. Soc. Rev. 2013, 42, 7214-7243.

(10) Schattling, P.; Jochum, F. D.; Theato, P. Multi-stimuli responsive polymers - the all-in-one talents. Polym. Chem. 2014, 5, 25-36.

(11) Seo, W.; Phillips, S. T. Patterned Plastics That Change Physical Structure in Response to Applied Chemical Signals. J. Am. Chem. Soc. 2010, 132, 9234-9235. 
(12) Lee, M. E.; Gungor, E.; Armani, A. M. Photocleavage of Poly(methyl acrylate) with Centrally Located o-Nitrobenzyl Moiety: Influence of Environment on Kinetics. Macromolecules 2015, 48, 8746-8751.

(13) Yeung, K.; Kim, H.; Mohapatra, H.; Phillips, S. T. Surface-Accessible Detection Units in Self-Immolative Polymers Enable Translation of Selective Molecular Detection Events into Amplified Responses in Macroscopic, Solid-State Plastics. J. Am. Chem. Soc. 2015, $137,5324-5327$.

(14) Neradovic, D.; van Nostrum, C. F.; Hennink, W. E. Thermoresponsive polymeric micelles with controlled instability based on hydrolytically sensitive N-isopropylacrylamide copolymers. Macromolecules 2001, 34, 7589-7591.

(15) Lo, C. L.; Lin, S. J.; Tsai, H. C.; Chan, W. H.; Tsai, C. H.; Cheng, C. H. D.; Hsiue, G. H. Mixed micelle systems formed from critical micelle concentration and temperaturesensitive diblock copolymers for doxorubicin delivery. Biomaterials 2009, 30, 3961-3970.

(16) Kot, E.; Bismarck, A. Polyacrylamide Containing Weak Temperature Labile Azo Links in the Polymer Backbone. Macromolecules 2010, 43, 6469-6475.

(17) Haseloh, S.; van der Schoot, P.; Zentel, R. Control of mesogen configuration in colloids of liquid crystalline polymers. Soft Matter 2010, 6, 4112-4119.

(18) Agarwal, S.; Grabe, N. Use of Reactive and Functional Hydrophobes (Hydrophobins) in the Miniemulsion Polymerization of Styrene and Methyl Methacrylate. Macromol. Chem. Phys. 2011, 212, 391-400.

(19) Grabe, N.; Zhang, Y.; Agarwal, S. Degradable Elastomeric Block Copolymers Based on Polycaprolactone by Free-Radical Chemistry. Macromol. Chem. Phys. 2011, 212, 13271334.

(20) Ueda, A.; Shiozu, Y.; Hidaka, Y.; Nagai, S. Studies on Block Copolymers Derived from Azobiscyanopentanoic Acid. Kobunshi Ronbunshu 1976, 33, 131-140.

(21) Ahn, T. O.; Kim, J. H.; Lee, J. C.; Jeong, H. M.; Park, J.-Y. Polyarylate-polystyrene block copolymer from macro-azoinitiator: Synthesis and its thermal properties. J. Polym. Sci., Part A: Polym. Chem. 1993, 31, 435-441.

(22) Hickenboth, C. R.; Rule, J. D.; Moore, J. S. Preparation of enediyne-crosslinked networks and their reactivity under thermal and mechanical conditions. Tetrahedron 2008, 64, 84358448 .

(23) Riedinger, A.; Guardia, P.; Curcio, A.; Garcia, M. A.; Cingolani, R.; Manna, L.; Pellegrino, T. Subnanometer Local Temperature Probing and Remotely Controlled Drug Release Based on Azo-Functionalized Iron Oxide Nanoparticles. Nano Lett. 2013, 13, 2399-2406.

(24) Saint-Cricq, P.; Deshayes, S.; Zink, J. I.; Kasko, A. M. Magnetic field activated drug delivery using thermodegradable azo-functionalised PEG-coated core-shell mesoporous silica nanoparticles. Nanoscale 2015, 7, 13168-13172. 
(25) Berkowski, K. L.; Potisek, S. L.; Hickenboth, C. R.; Moore, J. S. Ultrasound-induced sitespecific cleavage of azo-functionalized poly(ethylene glycol). Macromolecules 2005, 38, 8975-8978.

(26) Brandrup, J.; Immergut, E. H.; Grulke, E. A., Polymer handbook, 4th ed.; Wiley: New York; Chichester, 2004; p 2317.

(27) Oster, G.; Yang, N. L. Photopolymerization of Vinyl Monomers. Chem. Rev. 1968, 68, 125-151.

(28) Coote, M. L.; Lin, C. Y.; Zipse, H., The Stability of Carbon-Centered Radicals. In CarbonCentered Free Radicals and Radical Cations, Forbes, M. D. E., Ed. John Wiley \& Sons, Inc.: Hoboken, 2010; pp 83-104.

(29) Calvert, J. G.; Pitts, J. N., Photochemistry, Wiley: New York, 1966; p 899.

(30) Engel, P. S. Mechanism of the thermal and photochemical decomposition of azoalkanes. Chem. Rev. 1980, 80, 99-150.

(31) Weder, C.; Neuenschwander, P.; Suter, U. W.; Pretre, P.; Kaatz, P.; Gunter, P. New Polyamides with Large Second-Order Nonlinear Optical Properties. Macromolecules 1994, 27, 2181-2186.

(32) Phillips, R. E.; Soulen, R. L. Propylene Oxide Addition to Hydrochloric Acid - A Textbook Error. J. Chem. Educ. 1995, 72, 624-625.

(33) Crenshaw, B. R.; Weder, C. Self-assessing photoluminescent polyurethanes. Macromolecules 2006, 39, 9581-9589.

(34) Yamanaka, J.; Murai, M.; Yamada, H.; Ozaki, H.; Uchida, F.; Sawada, T.; Tomitama, A.; Ito, K.; Takiguchi, Y.; Taira, H. JP2006182833A, July 13, 2006.

(35) Takeda, T.; Goto, T.; Mori, Y. JP2003212917A, April 27, 2003. 
TOC Entry

\section{Azo-Containing Polymers with Degradation On-Demand Feature}

Mathieu A. Ayer ${ }^{l}$, Yoan C. Simon ${ }^{1,2}$, Christoph Weder ${ }^{1 *}$

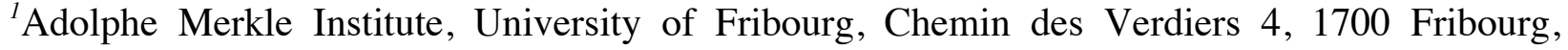

Switzerland

${ }^{2}$ School of Polymers and High Performance Materials, The University of Southern Mississippi,

118 College Dr., Hattiesburg MS 39406, USA

*E-mail: christoph.weder@unifr.ch (C.W.).
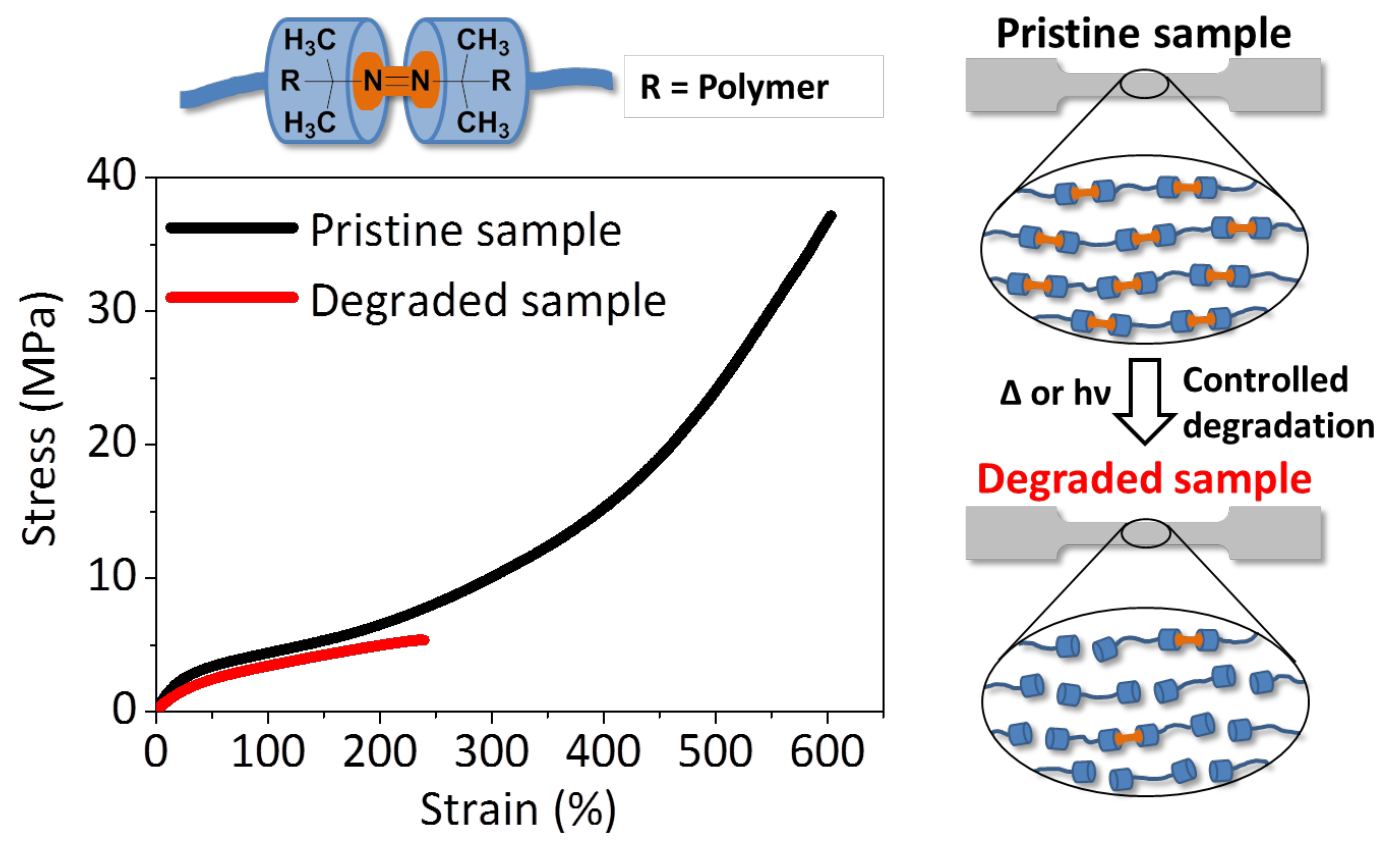